\title{
Impact of Shelf Valleys on the Spread of Surface-Trapped River Plumes
}

\author{
CANBo XiAO, ${ }^{\text {a }}$ WeIFEng Zhang, ${ }^{\text {b }}$ AND Ying CHEN $^{\mathrm{a}}$ \\ ${ }^{a}$ Ocean College, Zhejiang University, Zhoushan, China \\ ${ }^{\mathrm{b}}$ Applied Ocean Physics and Engineering Department, Woods Hole Oceanographic Institution, Woods Hole, Massachusetts
}

(Manuscript received 12 May 2020, in final form 20 October 2020)

\begin{abstract}
This study focuses on mechanisms of shelf valley bathymetry affecting the spread of riverine freshwater in the nearshore region. In the context of Changjiang River, a numerical model is used with different no-tide idealized configurations to simulate development of unforced river plumes over a sloping bottom, with and without a shelf valley off the estuary mouth. All simulated freshwater plumes are surface-trapped with continuously growing bulges near the estuary mouth and narrow coastal currents downstream. The simulations indicate that a shelf valley tends to compress the bulge along the direction of the valley long axis and modify the incident angle of the bulge flow impinging toward the coast, which then affects the strength of the coastal current. The bulge compression results from geostrophic adjustment and isobathfollowing tendency of the depth-averaged flow in the bulge region. Generally, the resulting change in the direction of the bulge impinging flow enhances down-shelf momentum advection and freshwater delivery into the coastal current. Sensitivity simulations with altered river discharges $Q$, Coriolis parameter, shelf bottom slope, valley geometry, and ambient stratification show that enhancement of down-shelf freshwater transport in the coastal current, $\Delta Q_{c}$, increases with increasing valley depth within the bulge region and decreasing slope Burger number of the ambient shelf. Assuming potential vorticity conservation, a scaling formula of $\Delta Q_{c} / Q$ is developed, and it agrees well with results of the sensitivity simulations. Mechanisms of valley influences on unforced river plumes revealed here will help future studies of topographic influence on river plumes under more realistic conditions.
\end{abstract}

KEYWORDS: Continental shelf/slope; Buoyancy; Coastal flows; Topographic effects; Runoff; Numerical analysis/modeling

\section{Introduction}

Freshwater injected from rivers into shelf seas in Northern Hemisphere, without being forced by external factors, tends to turn anticyclonically forming a coastal current in the direction of Kelvin wave propagation (Garvine 1995). This basic flow pattern (Fig. 1a) has been observed in river mouth areas, including Chesapeake Bay, Hudson River, and Changjiang River (e.g., Dzwonkowski and Yan 2005; Chant et al. 2008; Beardsley et al. 1985), as well as laboratory experiments (e.g., Avicola and Huq 2002, 2003a) and numerical models (e.g., Chao and Boicourt 1986; Fong and Geyer 2002).

One common feature of unforced river plumes is a continuously growing freshwater bulge with an anticyclonic outeredge flow that connects the river mouth and the downstream coastal current (e.g., Chen 2014; Yankovsky and Chapman 1997). As the flow finishes looping around the bulge impinging toward the coast, it splits into two branches: one heads back up-shelf toward the river mouth participating in the bulge recirculation and the other propagates down-shelf forming the coastal current. The growth of the bulge has been explained from two different perspectives:

1) Considering the bulge as a whole, Nof and Pichevin (2001) argued that the offshore extension of the bulge provides the down-shelf Coriolis force to balance the up-shelf momentum force associated with the down-shelf coastal current.

\footnotetext{
Corresponding author: Weifeng (Gordon) Zhang, wzhang@ whoi.edu
}

2) Considering local momentum balance in a box covering the location of the bulge flow impinging onto the coast (Fig. 1a), Whitehead (1985) explained that the downshelf coastal current results from the down-shelf momentum input of the incident bulge flow into the box and that the up-shelf recirculating flow exists when the incident bulge flow is not completely parallel to the coast toward down-shelf.

With a growing bulge, numerical models show that freshwater transport in the coastal current accounts for $27 \%-77 \%$ of the river discharge (Fong and Geyer 2002; Nof and Pichevin 2001; Chen 2014). Assuming slow variation, Nof and Pichevin (2001) constructed an inviscid analytical solution for freshwater transport in the coastal current $Q_{c}$ as

$$
\frac{Q_{c}}{Q}=\frac{1}{1+2 \xi / f}
$$

where $Q$ is the river discharge, $\xi$ is the bulge surface relative vorticity, and $f$ is Coriolis parameter (see Table A1 in appendix A for meanings of all notations). Fong and Geyer (2002) argued that $\xi / f$ is equivalent to the discharge Rossby number $\mathrm{Ro}_{d}=U_{0} /\left(W_{r} f\right)$ with $U_{0}$ being riverine outflow speed, and $W_{r}$ river mouth width. Thus,

$$
\frac{Q_{c}}{Q}=\frac{1}{1+2 \mathrm{Ro}_{d}} .
$$

Computing $Q_{c}$ using (1) would require a priori knowledge of the bulge circulation, while (2) does not. Whitehead (1985) argued that $Q_{c}$ depends on the incident angle of the bulge incident flow relative to the cross-shelf direction, $\beta_{i}$ (Fig. 1a). 
(a) Non-valley scenario

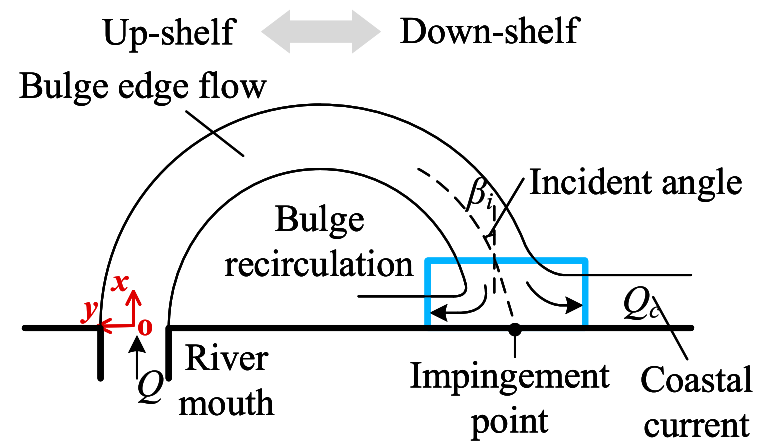

(b) Valley scenario

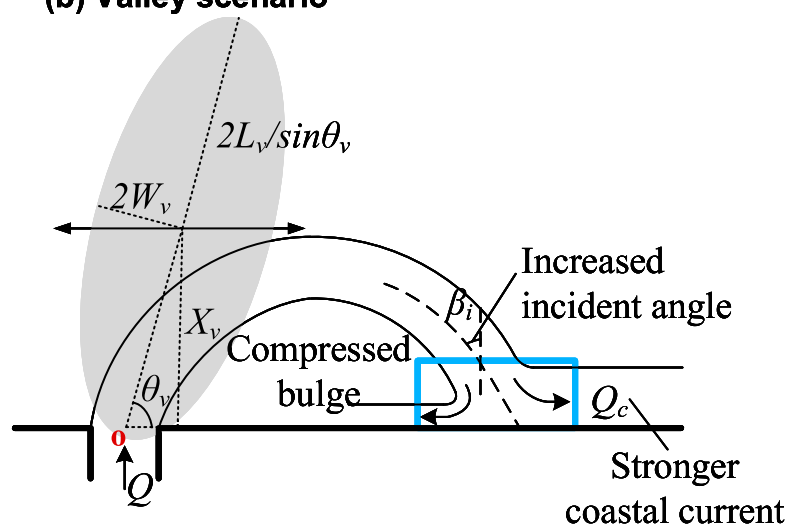

FIG. 1. Basic flow patterns of unforced river plumes in the Northern Hemisphere (a) without and (b) with a shelf valley. In (a), the anticyclonic bulge-edge flow impinges onto the coast with an incident angle $\beta_{i}$ and splits into opposite wall-bounded flows. In (b), the valley leads to a compressed bulge, increased incident angle, and stronger coastal current. Valley bathymetric anomaly is elliptical with a full length and width of $4 L_{v} / \sin \theta_{v}$ and $4 W_{v}$, respectively, and $\theta_{v}$ is the valley orientation angle relative to the coast. This setup ensures constant offshore location of the bulge center $X_{v}$ for different $\theta_{v}$.

When the bulge flow is normal to the coast $\left(\beta_{i}=0\right)$, approximately one-third of the river discharge goes into the bulge. As the bulge incident flow rotates toward the downshelf direction, both $\beta_{i}$ and alongshore momentum flux toward the coastal current increases. Consequently, the coastal current intensifies with more freshwater flowing down-shelf. Chen (2014) reported a similar relationship:

$$
\frac{Q_{c}}{Q}=0.34+0.53 \sin \beta_{i} .
$$

River plume structure and dispersal pattern are sensitive to coastal forcing, such as winds (e.g., Fong and Geyer 2001; Choi and Wilkin 2007; Jurisa and Chant 2013), tides (Chen 2014), and coastal geometry (Avicola and Huq 2003b). For instance, Chen (2014) demonstrated that tides can create an ageostrophic pressure gradient near the river mouth and compress the bulge shoreward against the coast, forming an elongated bulge. It increases $\beta_{i}$ and enhances freshwater transport in the coastal current.
Few studies have focused on influence of shelf bathymetry on unforced river plumes with growing bulges. Presumably, shelf bathymetry plays a secondary role in affecting this type of surface-trapped river plumes, compared to other forcing factors, such as winds and Coriolis force. Most of the aforementioned numerical and experimental studies used deep flat bottoms. In the real ocean, some surface-trapped river plumes, such as those of Changjiang and Hudson Rivers, exist over a sloping bottom with some form of irregular bathymetry underneath, such as shelf valleys, which are often submerged seaward extension of the ancestral river drainage system (e.g., Uchupi et al. 2001). Examples of shelf valleys near river mouths include Hudson Shelf Valley (Lentz et al. 2014), Umuda Valley (Crockett et al. 2008), "Swatch of No Ground" (Michels et al. 2003), and the valley off Changjiang River (Liu and Gan 2015). Similar to canyons over continental slopes (e.g., Allen and Durrieu de Madron 2009), shelf valleys are major transport conduit of heat, salt, sediment and nutrients (e.g., Harris et al. 2003; Manning et al. 1994). With a realistic model, Zhang et al. (2009) showed a strong influence of Hudson Shelf Valley on the Hudson River plume. Chen (2014) demonstrated that $Q_{c}$ increases by $8 \%$ when the flat bottom is changed to a slope with a slope parameter $\alpha_{s}=0.001$. With a series of idealized simulations, Lee and Valle-Levinson (2012, 2013) demonstrated the influence of shelf channels (narrow shelf valleys) on the estuary exchange flow, particularly, the subsurface return flow toward the estuary, and the behavior of the surface river plume on the shelf. However, the mechanism of a shelf valley modifying the pattern of surface river plume remains unclear.

This study is to elucidate mechanisms of shelf valleys adjacent to river mouths affecting the spread of unforced river plumes at the quasi-equilibrium states. Using idealized numerical simulations with no tides or surface forcing, we compare river plumes with and without shelf valleys and find that valleys tend to compress the bulge shoreward and enhance freshwater transport in the coastal current. Mechanisms of the valley influence are analyzed, and a scaling of the valleyinduced change of down-shelf freshwater transport is derived. The results agree well with the sensitivity simulations.

\section{Model description}

The hydrostatic Regional Ocean Modeling System (ROMS) is used with a rectangular domain of $530 \times 740 \mathrm{~km}^{2}$ in crossand along-shelf directions, respectively. An estuarine channel of $100 \mathrm{~km}$ long, $17 \mathrm{~km}$ wide, and $10 \mathrm{~m}$ deep delivers the freshwater into the shelf (Fig. 2). The coordinate system is defined as $x$ positive offshore, $y$ positive northward along-shelf, and $z$ positive upward with the origin at the center of the estuary mouth. An idealized shelf bathymetry consists of a linear sloping bottom and a valley as

$$
\begin{aligned}
& h=H_{c}+\alpha_{s} x+H_{v} e^{-\left|\mathbf{C R}\left(\hat{\mathbf{x}}-\mathbf{x}_{c}\right)\right|^{2}}, \\
& \mathbf{C}=\left[\begin{array}{cc}
\sin \theta_{v} / L_{v} & 0 \\
0 & 1 / W_{v}
\end{array}\right], \quad \mathbf{R}=\left[\begin{array}{cc}
\sin \theta_{v} & -\cos \theta_{v} \\
\cos \theta_{v} & \sin \theta_{v}
\end{array}\right],
\end{aligned}
$$



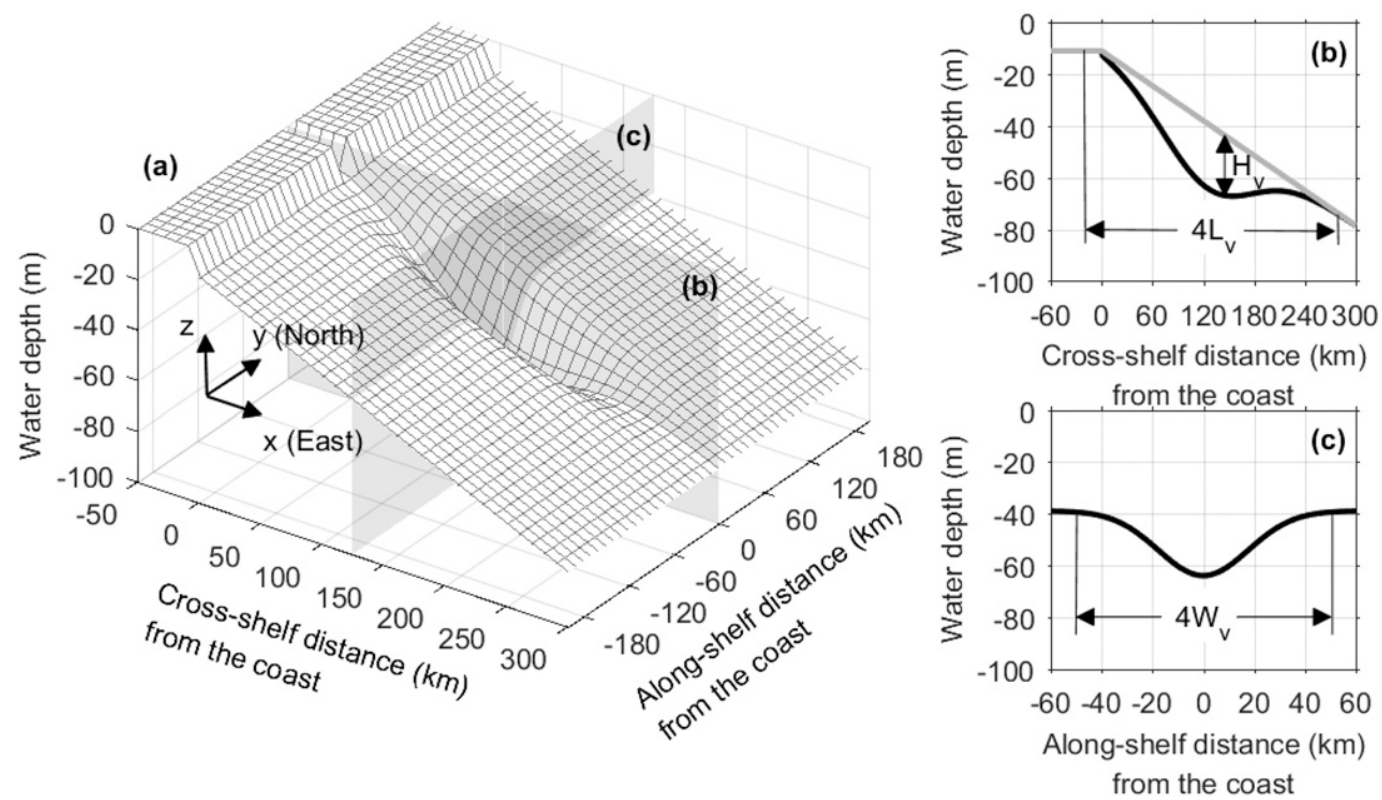

FIG. 2. (a) Model valley bathymetry in case RB1, (b) side-view of the bathymetry, and (c) along-shelf section of the bathymetry at $x=125 \mathrm{~km}$. The grid in (a) is 10 times coarser than the model grid in both $x$ and $y$ directions, and the area shown in (a) is only a part of the overall model domain. In (a), the shaded planes show the positions of the cross sections shown in (b) and (c). In (b), the gray line is the cross-shelf bathymetry of the ambient shelf, and the black line is the cross-shelf bathymetry along the valley axis.

Here, $\hat{\mathbf{x}}=(x, y), H_{c}$ is the depth on the coast; $\alpha_{s}$ is ambient bottom slope. The valley bathymetry, as represented by a Guassian-shaped function following Zhang and Lentz (2017), has a depth scale $H_{v}$, a width scale $W_{v}$, and a length scale parameter $L_{v}$ (see below); its center is at $\mathbf{x}_{c}=\left(X_{v}, Y_{v}\right)$. To consider influence of valley orientation, the valley is rotated around the origin with valley orientation angle $\theta_{v}$ defined as the angle from the negative $y$ direction to the valley long axis (Fig. 1b). Note that, during the rotation, $X_{v}$ is fixed, and the valley is stretched/squeezed in its long axis direction to maintain the cross-shelf extent of the valley. Hence, $Y_{v}=-X_{v} \cot \theta_{v}$, and the length scale of the valley is $L_{v} / \sin \theta_{v}$.

River input in the model is set up in the context of Changjiang River with a steady $Q \in[5,100] \times 10^{3} \mathrm{~m}^{3} \mathrm{~s}^{-1}$ in each simulation. The discharge water of $10^{\circ} \mathrm{C}$ and $0 \mathrm{psu}$ is injected at the head of the estuary channel and mixes with the estuary-inflow water before entering the shelf. Model initial temperature $T_{0}=10^{\circ} \mathrm{C}$ and salinity $S_{0}=32$ psu everywhere in all simulations. There is no wind, surface heat or salt fluxes, or tidal forcing in the model. Note that omission of tides in this study reduces mixing in the estuary and the river plume region, and causes the modeled river plumes to be artificially fresh. Meanwhile, the potential interaction between the tides and shelf bathymetry is also neglected. The influence of tides on the plume-bathymetry interaction is thus not considered here and is left for future studies.

Horizontal grid spacing is $1 \mathrm{~km} \times 1 \mathrm{~km}$ in the central study area of $460 \mathrm{~km} \times 600 \mathrm{~km}$ around the river mouth, and it increases outward reaching $7.4 \mathrm{~km}$ on the boundaries. The model has 20 sigma vertical layers with enhanced resolution near the surface. The top layer within the plume region is $\sim 0.5 \mathrm{~m}$ thick. Generic length scale (GLS) $k-k l$ vertical turbulence mixing scheme and quadratic bottom drag with drag coefficient, $C_{d}$, are used. The model is on a $\beta$ plane with $f=f_{0}+\beta y, f_{0}=7.49 \times$ $10^{-5} \mathrm{~s}^{-1}$, and $\beta \approx 1.98 \times 10^{-11} \mathrm{~m}^{-1} \mathrm{~s}^{-1}$, equivalent to $\sim 31^{\circ} \mathrm{N}$. Because of the small along-shelf extent of the plume, $\beta$ effect is negligible, as confirmed by test simulations. The western boundary is closed. The other three lateral boundaries are open with Chapman (1985) and Flather (1976) and radiation conditions for surface elevation, barotropic velocity, and threedimensional variables, respectively. Horizontal viscosity and diffusivity in the central study region are zero. Boundary sponge layers of $70 \mathrm{~km}$ wide with outward increasing viscosity and diffusivity are used to dissipate waves generated in the interior domain.

Three base runs (hereinafter, RB0, RB1, and RB2), differing by valley configurations, are employed to investigate the valley influence on river plumes. RB0 has no valley, and its shelf bathymetry is uniform in the along-shelf direction; in $\mathrm{RB} 1$, the valley is normal to the coast $\left(\theta_{v}=90^{\circ}\right)$; in $\mathrm{RB} 2$, the valley has $\theta_{v}=45^{\circ}$ mimicking the valley off the Changjiang River mouth. Other parameters in these runs are kept at their control values (Table 1). To explore a larger parameter space, 71 sensitivity simulations with valleys and altered values of 10 parameters, i.e., river discharge $(Q)$, Coriolis parameter $\left(f_{0}\right)$, shelf bottom slope $\left(\alpha_{s}\right)$, valley geometric parameters $\left(H_{v}, L_{v}\right.$, $\left.W_{v}, X_{v}, \theta_{v}\right)$, ambient stratification $\left(N_{a}\right)$, and bottom friction $\left(C_{d}\right)$, are carried out. There are thus a total of 10 sets of simulations, each of which is generated by altering the value of one parameter and keeping the others at their control values. 
TABLE 1 . Sensitivity parameters and key dimensionless numbers.

\begin{tabular}{|c|c|c|c|c|c|c|c|}
\hline Parameter & Symbol & Unit & Control value & Min value & Max value & Range of $\mathrm{Bu}$ & Range of Ro \\
\hline Valley depth scale & $H_{v}$ & $\mathrm{~m}$ & 25 & 5 & 45 & $0.10-0.13$ & $0.10-0.11$ \\
\hline Valley length scale parameter ${ }^{a}$ & $L_{v}$ & $\mathrm{~km}$ & 75 & 50 & 100 & $0.10-0.13$ & $0.10-0.11$ \\
\hline Valley width scale & $W_{v}$ & $\mathrm{~km}$ & 25 & 15 & 35 & $0.11-0.13$ & $0.09-0.11$ \\
\hline Valley orientation angle & $\theta_{v}$ & degree & 90 & 45 & 135 & $0.12-0.13$ & $0.11-0.12$ \\
\hline Offshore coordinate of the valley center & $X_{v}$ & $\mathrm{~km}$ & 125 & 105 & 145 & $0.11-0.13$ & $0.10-0.11$ \\
\hline River discharge & $Q$ & $10^{4} \mathrm{~m}^{3} \mathrm{~s}^{-1}$ & 3 & 0.5 & 10 & $0.09-0.15$ & $0.07-0.18$ \\
\hline Coriolis parameter ${ }^{\mathrm{b}}$ & $f_{0}$ & $10^{-5} \mathrm{~s}^{-1}$ & 7.49 & 2.78 & 11.3 & $0.10-0.21$ & $0.07-0.16$ \\
\hline Ambient shelf bottom slope & $\alpha_{s}$ & $10^{-4}$ & 2.25 & 1 & 9.75 & $0.06-0.26$ & $0.08-0.13$ \\
\hline Ambient stratification & $N_{a}$ & $10^{-2} \mathrm{~s}^{-1}$ & 0 & 0 & 2 & 0.13 & 0.11 \\
\hline Bottom drag coefficient & $C_{d}$ & $10^{-3}$ & 3 & 1 & 20 & 0.13 & 0.11 \\
\hline
\end{tabular}

${ }^{\text {a }}$ The actual length scale of the valley is $L_{v} / \sin \theta_{v}$.

${ }^{\mathrm{b}}$ At the latitude of the estuary.

Each sensitivity run with a valley has a no-valley counterpart for comparison.

Two dimensionless numbers: the slope Burger number

$$
\mathrm{Bu}=\frac{N_{s} \alpha_{s}}{f_{0}}
$$

measuring the influence of stratification in the presence of rotation and a sloping bottom, and Rossby number

$$
\mathrm{Ro}=\frac{|\zeta|}{f_{0}}
$$

measuring the effect of nonlinear advection versus rotation for depth-averaged flow in the bulge region are considered. Here, $N_{s}=\left(g^{\prime} / H\right)^{1 / 2}$ is buoyancy frequency in the bulge area; $\zeta$ is relative vorticity of depth-averaged flow within the bulge; $g^{\prime}=$ $g\left(\rho_{b}-\rho_{s}\right) / \rho_{0}$ is reduced gravity based on the mean bottom and surface density within the bulge, $\rho_{b}$ and $\rho_{s}$, respectively; and $H$ is the mean water depth within the bulge. In the base runs, $\mathrm{Bu} \approx 0.13$ and $\mathrm{Ro} \approx 0.11$; All sensitivity simulations have $\mathrm{Bu} \in[0.06,0.26]$ and $\mathrm{Ro} \in[0.07,0.18]$, indicating the dominance of Coriolis force in all modeled plumes.

\section{Model results}

\section{a. General plume pattern}

We first compare the base simulations to develop a general sense of the valley influence on the river plume. With no valley (RB0), a typical anticyclonic bulge forms and grows with time (Fig. 3). At day 27, when the plume reaches a quasi-equilibrium state, the bulge has a cross-shelf width of $W_{b} \approx 85 \mathrm{~km}$ and a radius of $R_{b} \approx 60 \mathrm{~km}$. Note that the plume boundary in the modeled field is defined in this study with a salinity cutoff of $31.5 \mathrm{psu}$ and bulge radius is defined as the distance from the rotation center to the bulge boundary. At day $27, W_{b}$ and $R_{b}$ are about 7 and 5 times of the baroclinic deformation radius of the plume of $L_{b} \approx 12 \mathrm{~km}$, respectively. Here, $L_{b}=\left(g^{\prime} H_{p}\right)^{1 / 2} / f$ (Lentz and Helfrich 2002); $H_{p}=\left(2 Q f / g^{\prime}\right)^{1 / 2} \approx 5.5 \mathrm{~m}$ is the plume thickness scale; $Q=3 \times 10^{4} \mathrm{~m}^{3} \mathrm{~s}^{-1}$; and the reduced gravity $g^{\prime} \approx 0.15 \mathrm{~m} \mathrm{~s}^{-2}$ is calculated based on average outflow density at the estuary mouth. While $L_{b}$ remains largely steady over the simulations, $R_{b} / L_{b}$ grows in time approximately following the trend of $t^{0.4}$ (appendix B), close to the relationship of $R_{b} / L_{b} \sim t^{0.39}$ reported by Horner-Devine et al. (2006).

Because this study focuses on the mechanism of valley bathymetry affecting the river plume, we choose to analyze the plume dynamics in the quasi-equilibrium state on day 27. Forced by tides, winds, and shelf currents, river plumes in the real ocean vary over much shorter time scale. Temporal variation of a real plume is often a major factor in its dynamics and obscure the analysis on the bathymetric influence. Examining the plume behavior in the quasi-equilibrium state allows us to separate the valley influence from the plume transient variation and then to focus on the dynamics of the bathymetric influence.

In RB0, plume-layer-averaged cross-shelf momentum balance on day 27 along a cross-shelf line going through the bulge center (Fig. 4a) shows a largely geostrophic balance between pressure gradient and Coriolis forces. Contribution of momentum advection (i.e., centrifugal force) to the balance is visible but secondary. Other terms are all negligible. Surface azimuthal velocity on the same cross-shelf section shows a quasi-linear profile (Fig. 4b), consistent with a rigid-body rotation within the bulge (Chen 2014). The maximum azimuthal velocity occurs near the outer boundary of the bulge with a strong lateral shear on its outskirt. The isohalines in the bulge exhibit a parabolic shape with the maximum plume thickness near the rotation center (Fig. 3b). Most of the freshwater in the bulge is surface-trapped. Horizontal flow in the bulge is surface-intensified with a strong vertical shear toward the outer edge of the bulge, consistent with the strong lateral density gradient there. Note that weak subsurface current of $O(0.01) \mathrm{m} \mathrm{s}^{-1}$ exists below the bulge base (Fig. 3b), which is consistent with the weak subsurface shoreward return flow underneath a river plume reported by Brasseale and MacCready (2020, manuscript submitted to J. Phys. Oceanogr.) and Masse (1990). This weak subsurface current connects the surface-trapped plume to the bottom and has important implication for the plume behavior (see below).

To the south end of the bulge, the bulge flow impinges toward the coast with an incident angle, $\beta_{i} \approx 32.5^{\circ}$ (Fig. 3a). The impinging flow then transitions to a narrow surface-intensified coastal current further down-shelf (Fig. 3c). At $y=-200 \mathrm{~km}$, 

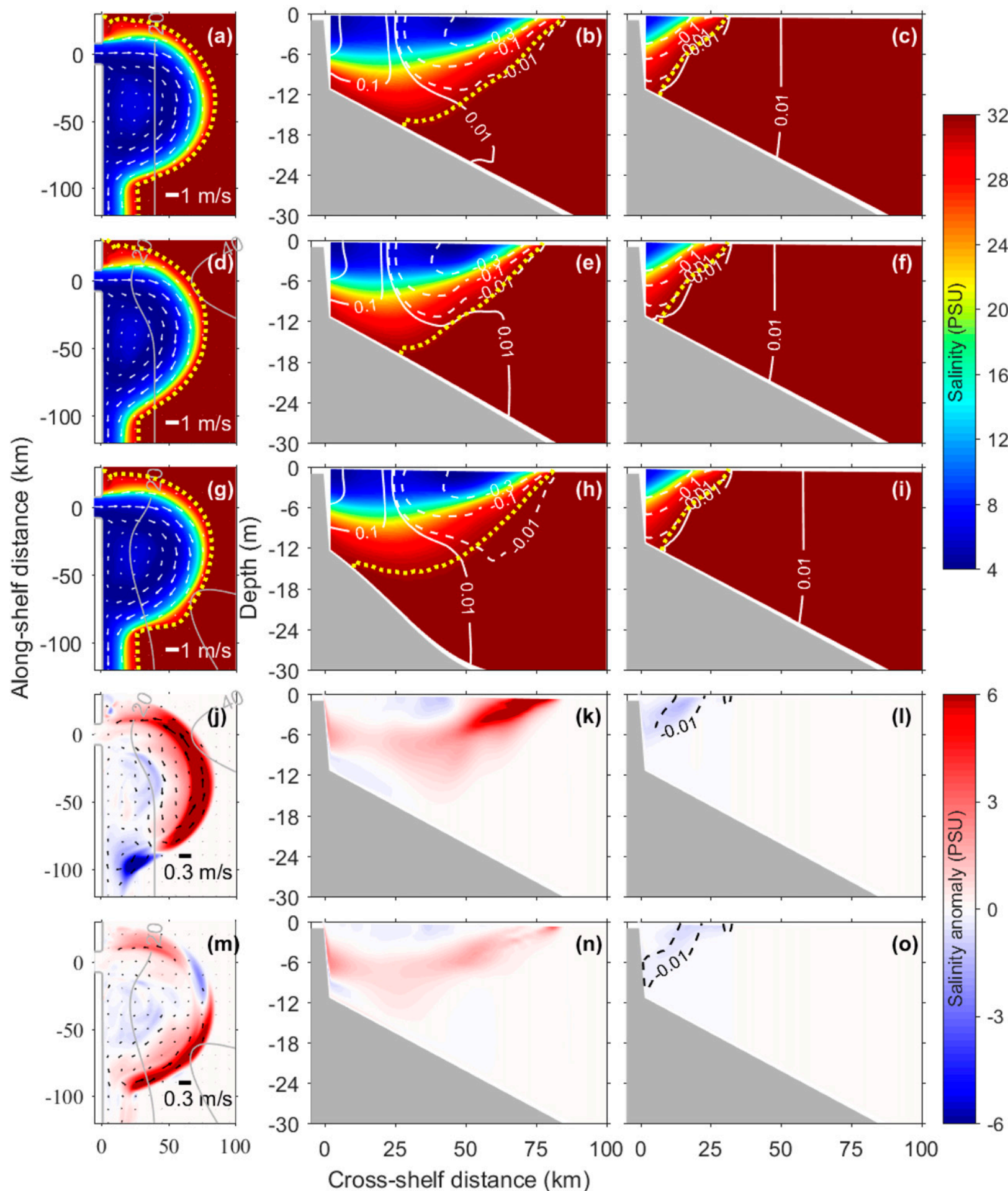

FIG. 3. Snapshots of the unforced river plume on day 27 in (first row) RB0, (second row) RB1, and (third row) RB2: (a),(d),(g) surface salinity (color) and velocity (arrows), and cross-shelf transects of salinity and contours of along-shelf velocity of \pm 0.01 , \pm 0.1 , and $\pm 0.3 \mathrm{~m} \mathrm{~s}^{-1}$ [in (b), (c), (e), (f), (h), and (i), thin solid white lines are up-shelf and thin dashed white lines are down-shelf] (b), (e), (h) at $y=-40 \mathrm{~km}$ in the middle of the bulge and (c),(f),(i) at $y=-200 \mathrm{~km}$ across the down-shelf coastal current. Anomalies of (fourth row) RB1 (RB1-RB0) and (fifth row) RB2 (RB2-RB0) from RB0: (j),(m) surface salinity and velocity anomalies, cross-shelf transect of salinity and along-shelf velocity anomalies at (k),(n) $y=-40 \mathrm{~km}$ and (1),(o) $y=-200 \mathrm{~km}$. The outer edges of the plumes at salinity of 31.5 psu are marked by yellow dotted lines in (a)-(i), the thick line in the left panels shows scales of the velocity vectors in each panel, and the solid gray lines in the left panels are bathymetric contours. 

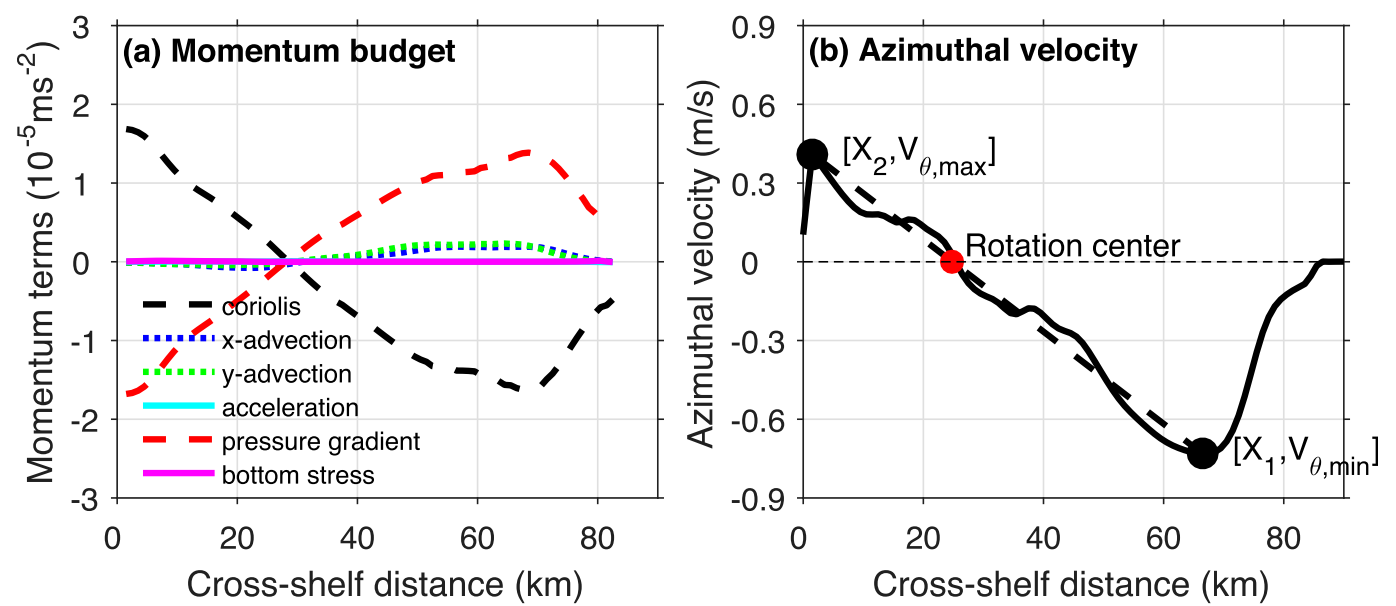

FIG. 4. (a) Cross-shelf momentum terms, vertically averaged over the bulge thickness, along $y=-40 \mathrm{~km}$ (across the bulge's rotational center) in RB0 and (b) corresponding cross-shelf profile of surface azimuthal velocity. In (b), $X_{1}$ and $X_{2}$ indicate the cross-shelf locations of azimuthal velocity reaching minimum, $V_{\theta, \min }$, and maximum, $V_{\theta, \max }$, respectively.

the coastal current has a maximum surface speed of $0.4 \mathrm{~m} \mathrm{~s}^{-1}$ and is mostly under thermal wind balance with isohalines shoal toward offshore. The weak subsurface return flow also extended down-shelf along with the coastal current (Fig. 3c). Similar to the result in Brasseale and MacCready (2020, manuscript submitted to J. Phys. Oceanogr.), it exists underneath of the coastal current and also extends further offshore. At $y=-200 \mathrm{~km}$, the northward volume transport of the subsurface return flow is about $1.0 \times 10^{4} \mathrm{~m}^{3} \mathrm{~s}^{-1}$, which is smaller than the southward coastal current volume transport of $4.2 \times$ $10^{4} \mathrm{~m}^{3} \mathrm{~s}^{-1}$. At day 27 , the freshwater flux in the coastal current, $Q_{c}$, accounts for $\sim 69 \%$ of the total river freshwater discharge $Q$. Here, $Q_{c}$ is computed as

$$
Q_{c}=-\int_{A_{c}}\left(\frac{S_{0}-S}{S_{0}}\right) v d A,
$$

where $A_{c}$ is cross-sectional area of the coastal current, $S$ is model salinity, and $v$ is along-shelf velocity. All $Q_{c}$ in this study is averaged in the along-shelf direction between $y=-180 \mathrm{~km}$ and $-200 \mathrm{~km}(80-100 \mathrm{~km}$ south of the bulge) to remove the influence of small-scale instability.

Adding valleys changes the plume structure slightly (Fig. 3). Both RB1 and RB2 give narrower (in the cross-shelf direction) bulges when compared to RB0. The incident angles of the coast-impinging flow at the south ends of the bulges in RB1 and RB2 are $43.8^{\circ}$ and $33.2^{\circ}$, respectively, both are slightly larger than that in RB0. However, the differences are small and difficult to see in the full model field. To show the valley influence, anomalies of RB1 and RB2 relative to RB0 are computed (Figs. 3j-O). Figure $3 \mathrm{j}$ shows a positive surface salinity anomaly band of $\sim 7 \mathrm{~km}$ wide along the eastern edge of the bulge, indicating the bulge in RB1 is $\sim 7 \mathrm{~km}$ narrower than in RB0. The negative salinity anomaly at the southern end of the bulge indicates that the bulge has extended slightly down-shelf. Thus, the valley compresses the bulge in the cross-shelf direction. A consistent pattern can be seen from the RB1 surface velocity anomaly with reduced southward flow on the outer edge and enhanced southward flow inside the bulge. On the cross section, the pattern of narrower bulge extends to the base of the bulge (Fig. 3k). Meanwhile, the negative velocity and salinity anomalies on the cross section of the coastal current indicate that the coastal current in RB1 is faster and fresher compared to RB0 (Fig. 31). Overall, $Q_{c}$ accounts for $73 \%$ of $Q$ in in RB1, $4 \%$ higher than in RB0.

Decreasing $\theta_{v}$ to $45^{\circ}$ leads to qualitative similar anomaly patterns (Figs. $3 \mathrm{~m}-\mathrm{o}$ ), i.e., a compressed bulge along with a slightly strengthened coastal current. Different from RB1, the direction in which the bulge in RB2 is compressed is no longer normal to the coast but to the northwest aligned mostly with the valley long axis. The $Q_{c} / Q$ in RB2 is enhanced by $1.7 \%$, less than that in RB1. Noting that the alternating positive and negative salinity anomalies on the bulge outskirt in RB2 is due to weak baroclinic instability developing on the bulge edge. It occurs in several simulations and does not affect the main pattern.

These valley-induced variations in bulge shape and freshwater transport are small compared to those induced by the addition of along-shelf tides (Chen 2014). However, they are associated with pronounced changes in the bulge circulation (see below). Test simulations suggest that these valley-induced small variations in the bulge shape can lead to different freshwater dispersal pattern on the shelf at a later stage when external forcing, such as winds and tides, are introduced (not shown).

We now use the freshwater thickness to demonstrate the changes in the horizontal plume spreading. Following Choi and Wilkin (2007), vertically integrated freshwater thickness is defined as

$$
H_{f}=\int_{-h}^{\eta} \frac{S_{0}-S}{S_{0}} d z
$$

where $\eta$ the sea surface height. With no valley (Fig. 5a), the horizontal distribution of $H_{f}$ shows a maximum thickness of 


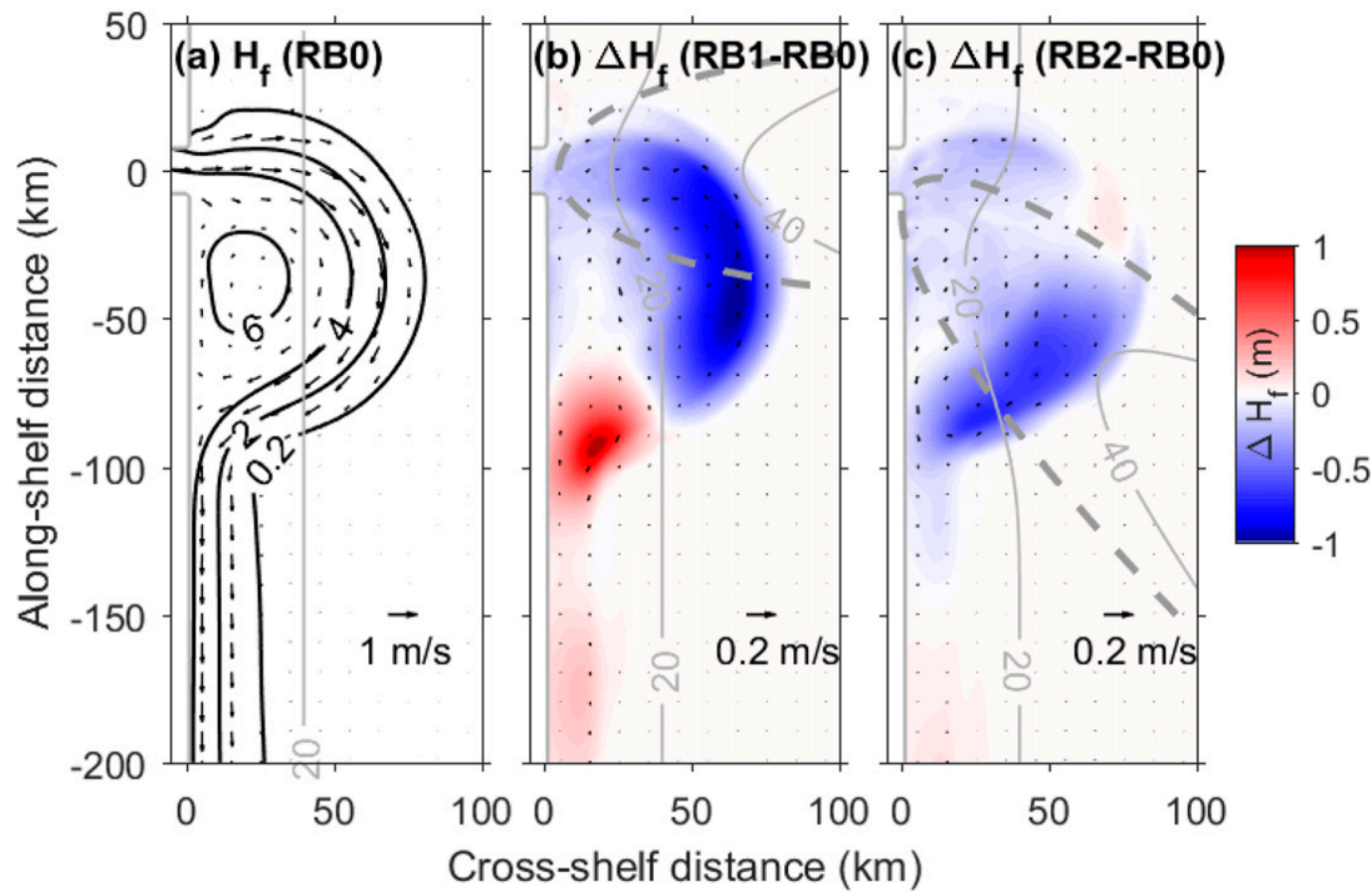

FIG. 5. (a) Freshwater thickness distribution (contours) and surface velocity (arrows) on day 27 in RB0, and the anomalies of freshwater thickness (color) and surface velocity (arrows) in (b) RB1 and (c) RB2 relative to RB0. The solid gray lines in (a)-(c) are bathymetric contours; the dashed gray lines in (b) and (c) highlight the edges of the valleys.

about $8 \mathrm{~m}$ at the bulge center, and it decreases outward toward the bulge edge. In the coastal current, $H_{f}=4.2 \mathrm{~m}$ on the coast and decreases offshore. The freshwater thickness is significantly altered when a valley is added. In both RB1 and RB2, $H_{f}$ in the bulge is greatly reduced with respect to RB0 (Fig. 5). The models show that valleys cause the bulge to continuously lose freshwater. At day 27, the maximum reduction in $H_{f}$ reaches $1 \mathrm{~m}$ in RB1 and $0.5 \mathrm{~m}$ in RB2, both locate toward the outer edge of the bulge where the original $H_{f}$ is $\sim 2 \mathrm{~m}$. The bulge freshwater loss is larger in RB1 than in RB2, which is consistent with the higher percentage enhancement of $Q_{c}$ in RB1. Such increase in $Q_{c}$ is responsible for the increased $H_{f}$ in the coastal current. As time proceeds, $H_{f}$ anomalies in the bulges grow in both RB1 and RB2, but those in the coastal currents become stable.

\section{b. Temporal evolution}

We now examine valley influence on temporal evolution of the bulge width $W_{b}$, bulge rotary flow, and $Q_{c}$. With and without a valley, $W_{b}$, defined as the bulge's maximum offshore extension, shows similar increasing trend with time (Fig. 6a). In all base runs, rapid increases of $W_{b}$ at the beginning reflect the initial formation of the bulge. The growth rates decrease gradually with time, but the bulge growth never stops. After day $20, W_{b}$ increases at a rate proportional to $t^{1 / 3}$, slightly slower than the rate of $R_{b}$ increase $\left(t^{0.4}\right)$. This modeled rate of $W_{b}$ increase is within the range of $t^{1 / 4}-t^{1 / 2}$ that other studies (e.g., Fong and Geyer 2002; Nof and Pichevin 2001) have reported. Starting from day $7, W_{b}$ in the simulations starts to diverge, and the difference grows gradually over time. After Day $25, W_{b}$ in RB1 is $5-9 \mathrm{~km}$ smaller than in RB0, and $W_{b}$ in $\mathrm{RB} 2$ is $0-4 \mathrm{~km}$ smaller than in RB0. Note that $W_{b}$ shows smallamplitude fluctuations with the period of $\sim 10$ days on top of the generally increasing trend. The fluctuations result from weak baroclinic instability developing on the bulge periphery. To remove its influence, model snapshot quantities are computed hereafter as averages over the 10 day period of day 22-31. Over that period, the bulge in RB1 is compressed shoreward on average by $\sim 7 \mathrm{~km}$ when compared to RB0, and the bulge in RB2 is compressed shoreward by $\sim 1.5 \mathrm{~km}$. However, the change of $W_{b}$ in RB2 does not fully reflect the influence of the slanted valley as the bathymetric influence rotates with the valley (see below).

Temporal evolution of the rotational speed of the bulge surface flow, $|\omega|$, in all base runs shows a decreasing trend with a rapid drop at the beginning transitioning to slower decreases at later stages. This trend of $|\omega|$ changing is opposite to that of $W_{b}$ and consistent with the Bernoulli's principle. Considering the bulge circulation as a rigid-body rotation, the azimuthal velocity of the water at the outer edge of the bulge, $v_{a}=R_{b} \omega$, where $R_{b}$ is the bulge radius. Chen (2014) demonstrated that water at the outer edge of the bulge stems from the northern corner of the river mouth following a streamline of constant pressure. According to Bernoulli's principle, $v_{a}$ along the streamline is constant and determined by the river outflow condition. Therefore, as the bulge grows and $R_{b}$ increases, $|\omega|$ 

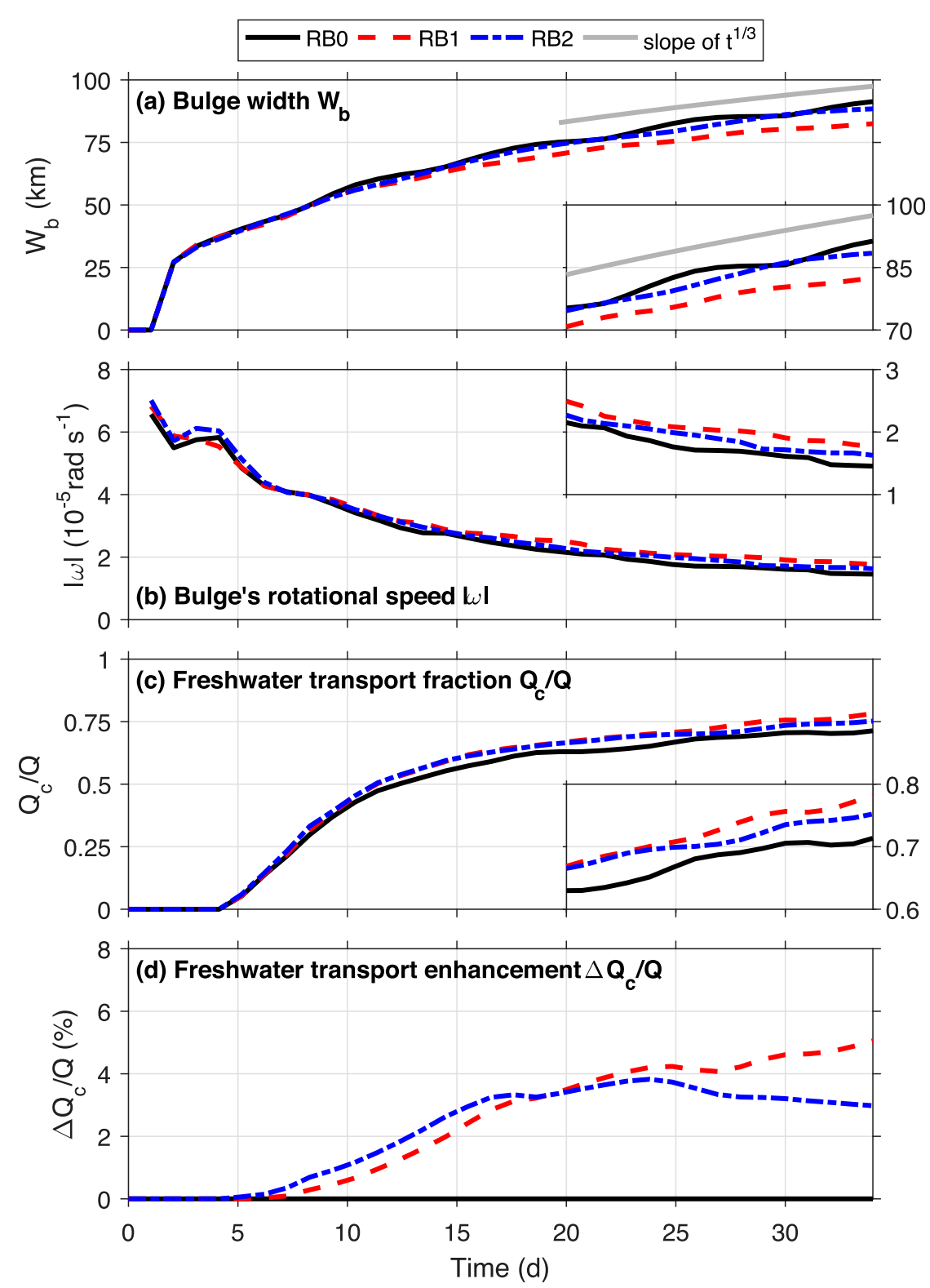

FIG. 6. Time series of (a) the bulge width $W_{b}$ (determined by the maximum offshore extent of $S=31.5 \mathrm{psu}$ ), (b) averaged surface rotational speed within the bulge $|\omega|$ [calculated as $\left(V_{\theta, \min }-V_{\theta, \max }\right) /\left(X_{1}-X_{2}\right)$; see Fig. 4b], (c) freshwater transport in coastal currents (averaged between $y=-180 \mathrm{~km}$ and $-200 \mathrm{~km}$ ), and (d) valley-induced enhancement of freshwater transport in the coastal current for RB0 (black solid line), RB1 (red dashed line), and RB2 (blue dash-dotted line). The small inset in each panel is a zoom-in view of the data from day 20 to the end of simulations. In (a), the gray dotted line shows the slope of $t^{1 / 3}$.

decreases; at the later stage, as the rate of $R_{b}$ increasing reduces, so does the rate of $|\omega|$ decreasing. This general relationship applies to all base runs. At the later stage, $|\omega|$ diverges among the base runs along with $W_{b}$. The bulge rotary flow is faster in RB1 and RB2 than in RB0 as the valley compresses the bulge and reduces $R_{b}$.

Temporal evolution of $Q_{c} / Q$ shows a consistent pattern among the base runs, but their values differ slightly (Fig. 6c).
Starting from day 4, coastal currents in all base runs intensifies steadily and carry more and more freshwater down-shelf. At day 10 , about $50 \%$ of the river discharge is carried down-shelf. After that, $Q_{c} / Q$ in all base runs rise more slowly. Toward the end of the simulations, $Q_{c}$ account for $70-80 \%$ of the river discharge. Adding a valley leads to a slight but persistent increase of $Q_{c}$ throughout the simulations (Fig. 6d). Normalized enhancement of $Q_{c}$ in $\mathrm{RB} 1$ and $\mathrm{RB} 2$ relative to $\mathrm{RB} 0, \Delta Q_{c} / Q$, 
increases from 0 at day 4 to $3.4 \%$ at day 20 . After that, as the plume reaches a quasi-equilibrium state, $\Delta Q_{c} / Q$ reaches a plateau with a slow increase in RB1 and a slow decrease in $\mathrm{RB} 2$. On day $27, \Delta Q_{c} / Q$ is $4.1 \%$ in $\mathrm{RB} 1$ and $3.3 \%$ in $\mathrm{RB} 2$.

\section{Governing mechanism}

The base runs have shown that shelf valleys tend to compress the bulge shoreward and increase down-shelf freshwater transport in the coastal current. This section explores 1) the mechanism of valley compressing the bulge and 2) the link between bulge compression and enhancement of the downshelf freshwater transport.

\section{a. Geostrophic adjustment}

The river plumes of our interests are surface-trapped with surface-intensified flows. However, Chen's (2014) slopingbottom simulation and our base runs indicate that shelf bathymetry affects spreading of the plumes even when they are surface-trapped. Similarly, Lee and Valle-Levinson (2012, 2013) found that shelf channels modify the subsurface return flow at the estuary mouth and affects the surface plume flow on the shelf. Weak subsurface return flows underneath surface river plumes have also been identified in other numerical studies (e.g., Brasseale and MacCready 2020, manuscript submitted to J. Phys. Oceanogr.; Masse 1990). They reflect entrainment of the shelf water into the river. In particular, Brasseale and MacCready (2020, manuscript submitted to J. Phys. Oceanogr.) argued that the subsurface return flow (called inflow in their study) underneath the outer-edge of the surface plume extends the depth range of the vertical shear associated with the horizontal plume flow. Through thermal wind balance, the extended vertical shear of the horizontal velocity modifies the interface between the plume freshwater and ambient shelf water, and then the shape of the surface plume. Because the subsurface return flow is steered by the shelf bathymetry, it dynamically connects the shelf bathymetry and the surface plume flow.

Consistently, our simulations show that development of the surface plume induces finite-amplitude variation in the bottom pressure and bottom velocity in the coastal region (not shown), and the pattern of the weak near-bottom return flow underneath the bulge change with the shelf bathymetry (Fig. 3). We thus hypothesize that the shelf bathymetry affects the vorticity of the subsurface return flow, which alters the water-column vorticity and then the surface plume flow. This is consistent with the potential vorticity (PV) of the modeled depthaveraged flow in the plume region being largely conserved when the bathymetry is changed (see below). Our hypothesized vorticity argument is likely consistent with Brasseale and MacCready's (2020, manuscript submitted to J. Phys. Oceanogr.) idea of the thermal wind balance connecting the subsurface return flow with the shape of the surface plume. Verification of the hypothesis is beyond the scope of this work and left to future studies. Nevertheless, the response of the surface plume flow to the shelf bathymetry could be conceptually considered as a part of the response of the depthaveraged barotropic flow in the plume region to the shelf bathymetry. To investigate bathymetric influence on the surface plume, we first examine the depth-averaged crossshelf momentum balance

$$
\frac{\partial \bar{u}}{\partial t}+\overline{u \frac{\partial u}{\partial x}}+\overline{v \frac{\partial u}{\partial y}}=f \bar{v}-\frac{1}{\rho_{0}} \frac{\overline{\partial p}}{\partial x}+\frac{\tau_{b x}}{(h+\eta) \rho_{0}},
$$

on day 27 when the model reaches a quasi-equilibrium state. In (10), $u$ is cross-shelf velocity, $\rho_{0}$ is reference density, $p$ is pressure, $\tau_{b x}$ is bottom stress in cross-shelf direction, and overbar represents vertical average.

When the valley is normal to the coast (RB1), depth-average flow in the plume region shows a pattern similar to the surface plume flow (Fig. 7a). The depth-averaged momentum balance in the plume region is similar to the plume-layer-averaged momentum balance (Fig. 4a). It is dominated by the Coriolis (Fig. 7a) and pressure gradient (not shown) forces; nonlinear advection terms are secondary (Fig. 7b); and bottom friction is negligible (not shown). The acceleration term is also very small, compared to the other terms, meaning bulge growth does not contribute significantly to the cross-shelf momentum balance. Therefore, depth-averaged flows in the bulge and coastal current are mainly geostrophic. Note that depthintegrated momentum terms show similar pattern of momentum balance.

Anomalies of the cross-shelf momentum terms in RB1 relative to RB0 has a similar order: anomalies of Coriolis (Fig. 7e) and pressure gradient (not shown) dominate and largely balance each other; anomalies of momentum advection are secondary (Fig. 7f); and anomalies of acceleration and bottom friction terms are negligible (not shown). This indicates that adjustment of the depth-averaged flow in the bulge region to the valley bathymetry is largely a geostrophic response. Meanwhile, anomalies of the depth-averaged velocity in the bulge show a cyclonic pattern that tends to slow down the southward flow at the offshore edge of the bulge and accelerate the southward flow in the center of the bulge. Relative vorticity of the barotropic flow in the bulge region, $\zeta$, is thus strengthened (more negative), consistent with increased $|\omega|$ in RB1 (Fig. 6b).

Both the increase of $|\zeta|$ and the compression of the bulge in RB1 are consistent with PV conservation. Here, we define the $\mathrm{PV}$ of the barotropic flow in the bulge region as

$$
\Pi=\frac{f+\zeta}{H} .
$$

Increase of $|\zeta|$ in RB1 indicates the tendency of the system to compensate for the decrease of potential vorticity due to increased water depth. The increase in $|\zeta|$ from RB0 to RB1 is $2.2 \times 10^{-6} \mathrm{~s}^{-1}, \sim 3 \%$ of the absolute vorticity in the bulge region in RB0, $f+\zeta=7.5 \times 10^{-5} \mathrm{~s}^{-1}$. The mean water depth in the bulge region in $\mathrm{RB} 0$ is $H=17.4 \mathrm{~m}$. If the bulge in RB1 remained the same size as in RB0, $H$ would increase to $19.2 \mathrm{~m}$, i.e., the valley in RB1 would increase $H$ by $10.3 \%$. Thus, the $3 \%$ increase of absolute vorticity would not be enough to counterbalance the $H$ change induced by the valley if the bulge remained the same. In fact, the increase of $H$ in RB1 is greatly suppressed by onshore compression of the bulge to only $4.3 \%$, 


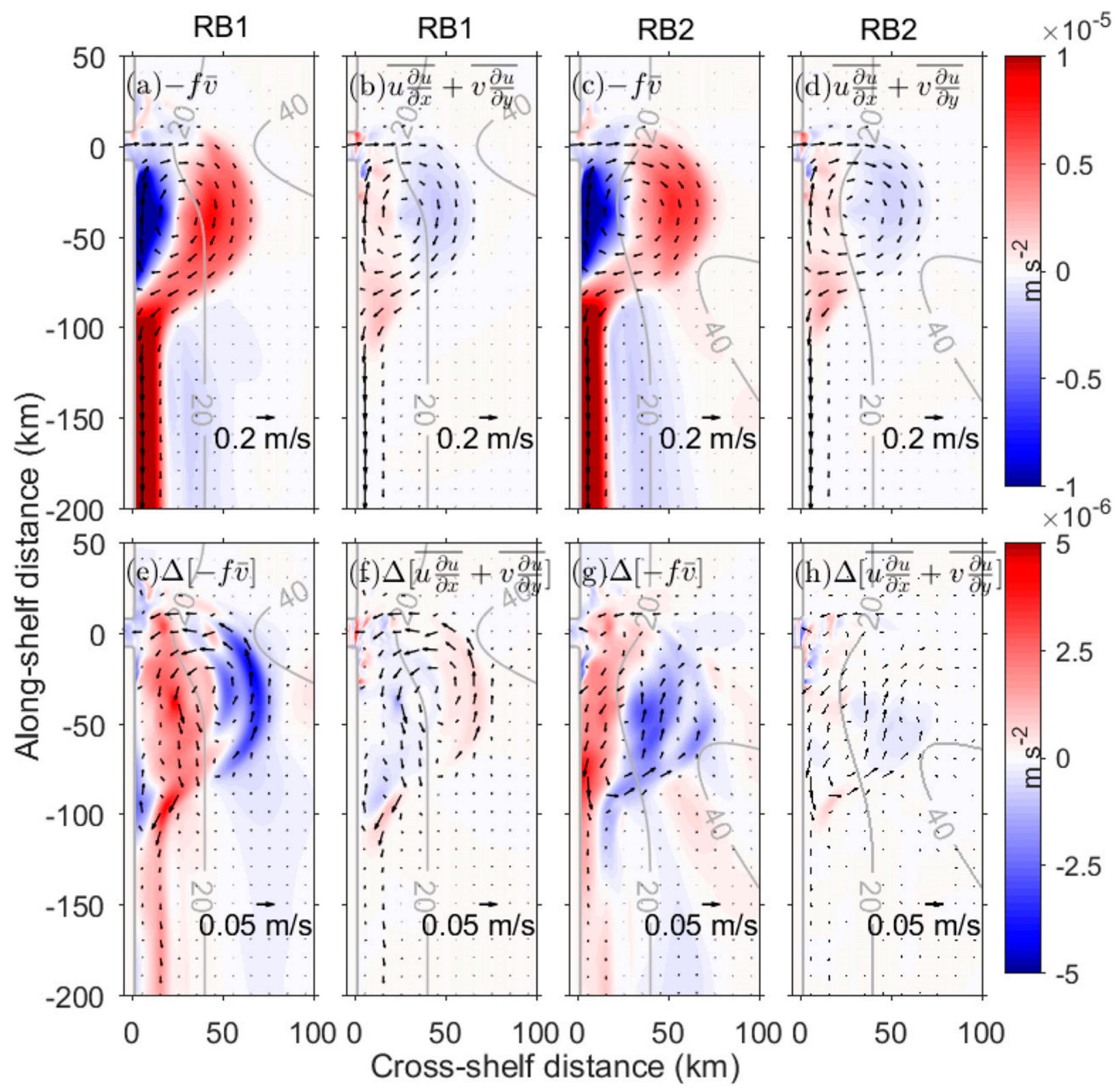

FIG. 7. Depth-averaged velocity (arrows) and cross-shelf momentum terms (color) in RB1 (left two columns) and RB2 (right two columns) and their anomalies relative to RB0: (a),(c) cross-shelf Coriolis term in RB1 and RB2, respectively, (b), (d) cross-shelf nonlinear momentum advection term in RB1 and RB2, respectively; (e), (g) anomalies of the cross-shelf Coriolis term in RB1 and RB2, respectively, relative to RB0; (f),(h) anomalies of the cross-shelf nonlinear advection term in RB1 and RB2, respectively, relative to RB0.

close to the $3 \%$ increase of absolute vorticity. As the result, the $\mathrm{PV}$ values of the barotropic flow in the bulge region are $4.31 \times$ $10^{-6} \mathrm{~m}^{-1} \mathrm{~s}^{-1}$ and $4.25 \times 10^{-6} \mathrm{~m}^{-1} \mathrm{~s}^{-1}$ in RB0 and RB1, respectively. This consistency indicates that, when a valley is added, the system tends to compress the bulge to conserve PV of the barotropic flow in the bulge region.

As the bulge being compressed in the cross-shelf direction, the incidence angle of the bulge flow impinging onto the coast, $\beta_{i}$, increases. In particular, $\beta_{i}$ is $11.3^{\circ}$ larger in RB1 than in RB0. Thus, the along-shelf momentum input of the bulge flow into a rectangular box around the impingement point (Fig. 1) across its offshore side increases in RB1. Following Whitehead's (1985) theory, the portion of freshwater going down-shelf, i.e., freshwater transport of the coastal current, $Q_{c}$, increases.

When the valley is slanted with $\theta_{v}=45^{\circ}(\mathrm{RB} 2)$, the general pattern of cross-shelf momentum balance (Figs. 7c,d) and its anomaly relative to RB0 (Figs. $7 \mathrm{~g}, \mathrm{~h}$ ) are similar to RB1. Changes of $\zeta$ and $H$ from RB0 to RB2 also largely counterbalance each other, resulting in PV conservation in the bulge region. However, $\beta_{i}$ in $\mathrm{RB} 2$ are only $0.7^{\circ}$ larger than that in 

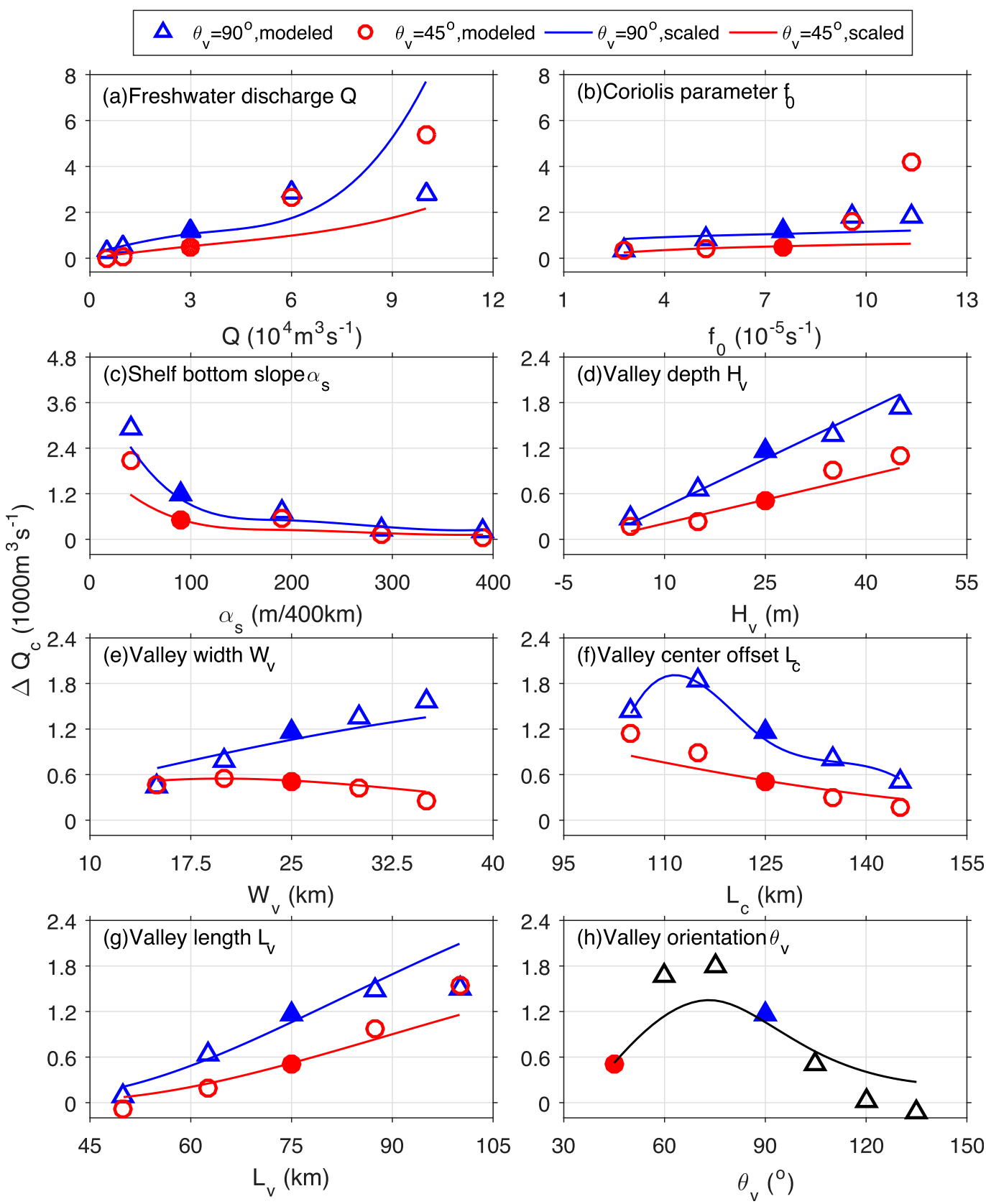

FIG. 8. (a)-(h) Dependence of valley-induced freshwater transport enhancement $\Delta Q_{c}$ on sensitivity parameters. The triangle and circle symbols represent sensitivity simulations in B1 and B2 regimes, respectively; the filled symbols represent the corresponding base runs; and the blue and red solid lines represent the predictions given by the scaled formula (32). The black symbols and the black solid line in (h) represent the runs of different valley orientation.

RB0, which is consistent with the smaller change in $Q_{c}$ (Figs. 6c,d). These small differences in RB2 and RB0 result from an upshelf compression of the bulge by the slanted valley and will be discussed in section 5 b.

\section{b. Parameter dependences}

We now examine the dependence of valley-induced enhancement of freshwater transport in coastal currents,
$\Delta Q_{c}=Q_{c, w}-Q_{c, o}$, on sensitivity parameters. Here, $Q_{c, w}$ and $Q_{c, o}$ are freshwater transport in coastal currents in simulations with and without the valley, respectively. (Hereafter, subscripts $w$ and $o$ denote variables with and without the valley, respectively.) Each value of $\Delta Q_{c}$ is computed from a pair of simulations with all parameters the same except the bathymetry: one with a valley and the other without. The sensitivity simulations show that $\Delta Q_{c}$ varies with $Q, f_{0}, \alpha_{s}, H_{v}, W_{v}, X_{v}, L_{v}$, 
and $\theta_{v}$ (Fig. 8), but not with $C_{d}$ and $N_{a}$ (not shown). Here, most of the sensitivity simulations are grouped into two regimes: B1 regime with $\theta_{v}=90^{\circ}$ and $\mathrm{B} 2$ regime with $\theta_{v}=45^{\circ}$. In both regimes, $\Delta Q_{c}$ has the same trends of parameter dependence for most of the parameters, except $W_{v}$. In most cases, $\Delta Q_{c}$ is greater in $\mathrm{B} 1$ regime than in $\mathrm{B} 2$ regime.

In both regimes, $\Delta Q_{c}$ increases monotonically with $Q$ and $f_{0}$ but decreases with $\alpha_{s}$. The dependences on $f_{0}$ and $\alpha_{s}$ can be understood from the slope Burger number $\mathrm{Bu}=N_{s} \alpha_{s} / f_{0}$, which measures the influence of water column stratification versus rotation. As $f_{0}$ increases, Bu decreases, stratification becomes less important, and the bulge flow is more connected to the valley bathymetry, causing greater influence of the valley on the plume and then greater $\Delta Q_{c}$. Increasing $\alpha_{s}$ has the opposite effect on $\mathrm{Bu}$ and then $\Delta Q_{c}$.

For the valley geometric parameters, $\Delta Q_{c}$ increases with increasing $H_{v}$ and $L_{v}$ and decreasing $X_{v}$ in both regimes; the dependences of $\Delta Q_{c}$ on $W_{v}$ differ in two regimes, and the dependences of $\Delta Q_{c}$ on $\theta_{v}$ is nonlinear. The positive relationship of $\Delta Q_{c}$ with $H_{v}$ and $L_{v}$ and the generally negative relationship of $\Delta Q_{c}$ with $X_{v}$ presumably reflects the influence of the valley geometry/location on mean water depth of the bulge region: as the valley becomes longer and deeper or moves closer to the coast, water depth in the bulge region increases, and the bulge is further compressed shoreward to conserve $\mathrm{PV}$. It then leads to larger $\beta_{i}$ and greater $\Delta Q_{c}$. The increase of $\Delta Q_{c}$ with $W_{v}$ in $\mathrm{B} 1$ regime is presumably caused by the same mechanism. The opposite dependence of $\Delta Q_{c}$ on $W_{v}$ in $\mathrm{B} 2$ regime and the nonlinear dependence of $\Delta Q_{c}$ on $\theta_{v}$ reflect up-shelf compression of the bulge by the slanted valley (section 5b). The dependence of $\Delta Q_{c}$ on $C_{d}$ and $N_{a}$ is not pronounced, consistent with bottom friction being negligible in the bulge momentum balance and stratification in the bulge being determined by the freshwater input from the river, rather than the weak ambient shelf stratification.

\section{Analytical scaling}

This section is to develop a scaling to quantitatively measure the influence of the shelf valleys on the river plume in its quasiequilibrium state. To be consistent with the quantity commonly used in the literature, we choose to examine valley-induced enhancement of freshwater transport in the coastal current in a quasi-equilibrium state of a fully developed unforced river plume. Three main assumptions are made here:

1) Valley-induced change of relative vorticity in the bulge region is much smaller than the absolute vorticity of the bulge, i.e., $\left|\left(\zeta_{w}-\zeta_{o}\right) /\left(f+\zeta_{o}\right)\right| \ll 1$.

2) Valley-induced change of mean water depth in the bulge region, $\Delta H$, is smaller than the original mean water depth within the bulge region, $H$, i.e., $\Delta H / H<1$.

3) PV of depth-averaged flow within the bulge region is conserved.

The first and second assumptions are satisfied in the parameter space of the interests of this study, as all simulations here have $\left(\zeta_{w}-\zeta_{o}\right) /\left(f+\zeta_{o}\right) \in[-0.014,0.011]$ and $\Delta H / H \in[0.1,0.2]$. The third assumption is largely valid, as shown in section $4 \mathrm{a}$,
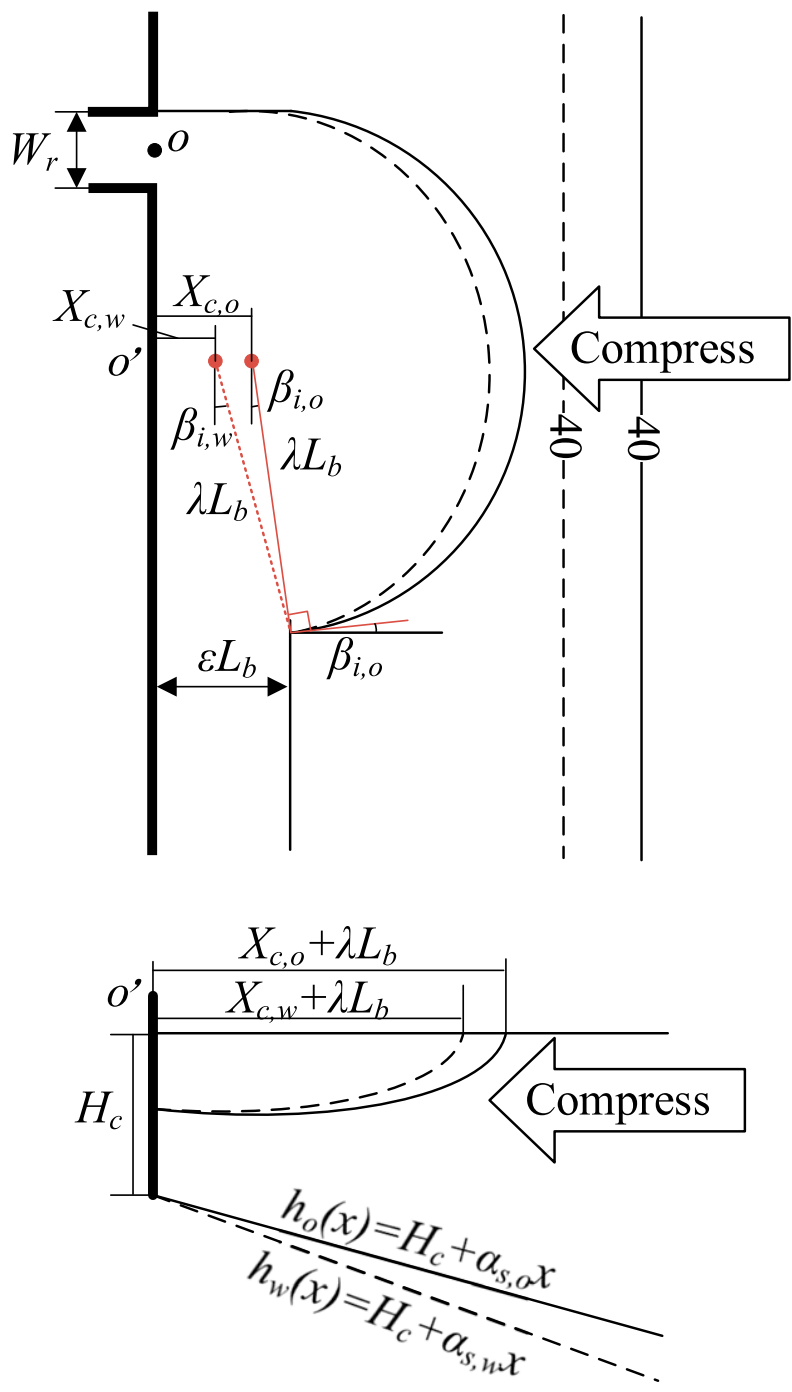

FIG. 9. Schematic illustration of the cross-shelf bulge compression in response to uniform increase of the bottom slope. Thin solid and dashed lines reflect the original and compressed scenarios, respectively, and black bold lines are the coastal wall. Parameters in cases with and without compression are labeled with the subscripts $w$ and $o$, respectively. Parameters with no such subscripts have identical values in both cases; $W_{r}$ is the estuary width, $H_{c}$ depth on the coast, $\alpha_{s}$ shelf bottom slope, $X_{c}$ the offshore position of the bulge rotation center, $\beta_{i}$ the incident angle of the bulge flow impinging toward the coast. Note that the bulge radius and the width of the coastal current are $R_{b}=\lambda L_{b}$ and $W_{c}=\varepsilon L_{b}$, respectively, where the baroclinic deformation radius $L_{b}=\left(2 Q g^{\prime}\right)^{0.25} / f^{0.75}$; $\lambda$ and $\varepsilon$ are empirical coefficients (appendix B).

and suggests that runs with different shelf bathymetry but same river input tend to have the same averaged PV in the bulge region.

\section{a. PV conservation}

We first consider the scenario of along-shelf uniform change of the bottom slope, $\alpha_{s}$, for simplicity (Fig. 9). Test simulations demonstrate that uniform increase of $\alpha_{s}$ compresses the bulge 
(not shown), similar to adding a valley of $\theta_{v}=90^{\circ}$. PV conservation gives

$$
\frac{f+\zeta_{w}}{H_{w}}=\frac{f+\zeta_{o}}{H_{o}}
$$

and then

$$
\frac{H_{w}-H_{o}}{H_{o}}=\frac{\zeta_{w}-\zeta_{o}}{f+\zeta_{o}}
$$

Here, $H_{w}$ and $H_{o}$ are mean water depth within the bulge regions with and without the slope change, respectively, i.e.,

$$
\begin{aligned}
& H_{o}=\frac{\int_{A_{b, o}}\left(H_{c}+\alpha_{s, o} x\right) d A}{A_{b, o}} ; \\
& H_{w}=\frac{\int_{A_{b, w}}\left(H_{c}+\alpha_{s, w} x\right) d A}{A_{b, w}},
\end{aligned}
$$

where $A_{b}$ is the bulge area. Inserting (14) and (15) into (13), assuming small changes of bottom slope, i.e., $\Delta \alpha=\left|\alpha_{s, o}-\alpha_{s, w}\right| \ll$ $\alpha_{s, o}$ and bulge width, i.e., $\Delta W^{\prime}=W_{b, o}^{\prime}-W_{b, w}^{\prime} \ll W_{b, o}^{\prime}$ (consistent with assumption 3 and requires $W_{b, o}^{\prime}$ and $\alpha_{s, o}$ being greater than zero), and neglecting the second-order terms yield

$$
\frac{W_{b, w}^{\prime}-W_{b, o}^{\prime}}{W_{b, w}^{\prime}}-\frac{H_{o}}{\alpha_{s, o} W_{b, w}^{\prime}} \frac{\zeta_{w}-\zeta_{o}}{f+\zeta_{o}} \approx-\frac{\alpha_{s, w}-\alpha_{s, o}}{\alpha_{s, o}} .
$$

Here, $W_{b, w}^{\prime}$ and $W_{b, o}^{\prime}$ are area-based width scales of the bulges with and without the slope change, respectively, and defined as

$$
W_{b, o}^{\prime}=\frac{\int_{A_{b, o}} x d A}{A_{b, o}} ; \quad W_{b, w}^{\prime}=\frac{\int_{A_{b, w}} x d A}{A_{b, w}} .
$$

Equation (16) indicates two possible approaches to conserve PV in response to bottom slope increase (i.e., decreasing right-hand side): (i) moving the bulge flow shoreward by decreasing $\left(W_{b, w}^{\prime}-W_{b, o}^{\prime}\right) / W_{b, w}^{\prime}$ and (ii) slowing down the anticyclonic bulge flow by increasing $\left(\zeta_{w}-\zeta_{o}\right) /\left(f+\zeta_{o}\right)$. Our simulations indicate that the system takes the first approach, i.e., bulge compression, as the second approach likely violates the momentum conservation of the river-to-bulge flow system.

We now seek to make (16) applicable to the scenarios of adding shelf valleys. The strategy is to derive a spatially uniform slope change, $\Delta \alpha=\alpha_{s, w}-\alpha_{s, o}$, that gives the same volume change in the bulge region, $\Delta V$, as adding a valley. That is,

$$
\int_{A_{b, o}} \Delta \alpha x d A=\Delta V
$$

As $\Delta \alpha$ is uniform in space, (17) and (18) together give

$$
\Delta \alpha=\frac{\Delta V}{A_{b, o} W_{b, o}^{\prime}}=\frac{\Delta H}{W_{b, o}^{\prime}},
$$

with $\Delta H$ denoting the mean depth increase within the bulge region caused by adding a valley. Substituting (19) into (16) gives

$$
\frac{W_{b, w}^{\prime}-W_{b, o}^{\prime}}{W_{b, w}^{\prime}}-\frac{H_{o}}{\alpha_{s, o} W_{b, w}^{\prime}} \frac{\zeta_{w}-\zeta_{o}}{f+\zeta_{o}} \approx-\frac{H_{o}}{\alpha_{s, o} W_{b, w}^{\prime}} \frac{\Delta H}{H_{o}} .
$$

Within the parameters space of the interests of this study, $\left(\zeta_{w}-\right.$ $\left.\zeta_{o}\right) /\left(f+\zeta_{o}\right) \in[-0.014,0.011]$ and $\Delta H / H_{o} \in[0.1,0.2]$. The second left-hand-side term of $(20)$ is much smaller than the right-hand-side term and thus neglected here for simplicity. This is consistent with the fact that models take the approach to compress the bulge, rather than slow down the anticyclonic bulge flow, when a valley is added. Equation (20) thus becomes

$$
W_{b, w}^{\prime}-W_{b, o}^{\prime} \approx-\frac{\Delta H}{\alpha_{s, o}} .
$$

The width scales of the bulges in (21), as shown in (17), are difficult to obtain analytically. We here take a pragmatic approach to replace $W_{b, w}^{\prime}-W_{b, o}^{\prime}$ with other more tractable variables. The analysis in appendix B shows that $W_{b, w}^{\prime}-W_{b, o}^{\prime}$ is proportional to $X_{c, w}-X_{c, o}$, where $X_{c, o}$ and $X_{c, w}$ are the offshore location of the bulge rotation center with and without the valley, respectively. We thus have

$$
\left(X_{c, w}-X_{c, o}\right) \sim \frac{\Delta H}{\alpha_{s, o}} .
$$

Equation (22) indicates that a deeper valley with greater $\Delta H$ tends to cause stronger shoreward bulge compression, while steepening the ambient shelf tends to diminish the bulge compression. Section 4 shows that onshore compression of the bulge increases $\beta_{i}$ and delivers more freshwater into the coastal current. To quantify the enhancement of the down-shelf freshwater transport, we define a normalized enhancement factor

$$
I=\frac{\Delta Q_{c}}{Q}
$$

Following (3), we have

$$
I \sim\left(\sin \beta_{i, w}-\sin \beta_{i, o}\right)
$$

where $\beta_{i, w}$ and $\beta_{i, o}$ are the bulge flow incident angle with and without the valley, respectively. Their difference is related to the cross-shelf migration of the bulge rotation center as (appendix B)

$$
\sin \beta_{i, w}-\sin \beta_{i, o}=\frac{X_{c, o}-X_{c, w}}{R_{b}} .
$$

Combining (22), (24), and (25) yields

$$
I \sim \frac{\Delta H}{\alpha_{s, o} R_{b}} .
$$




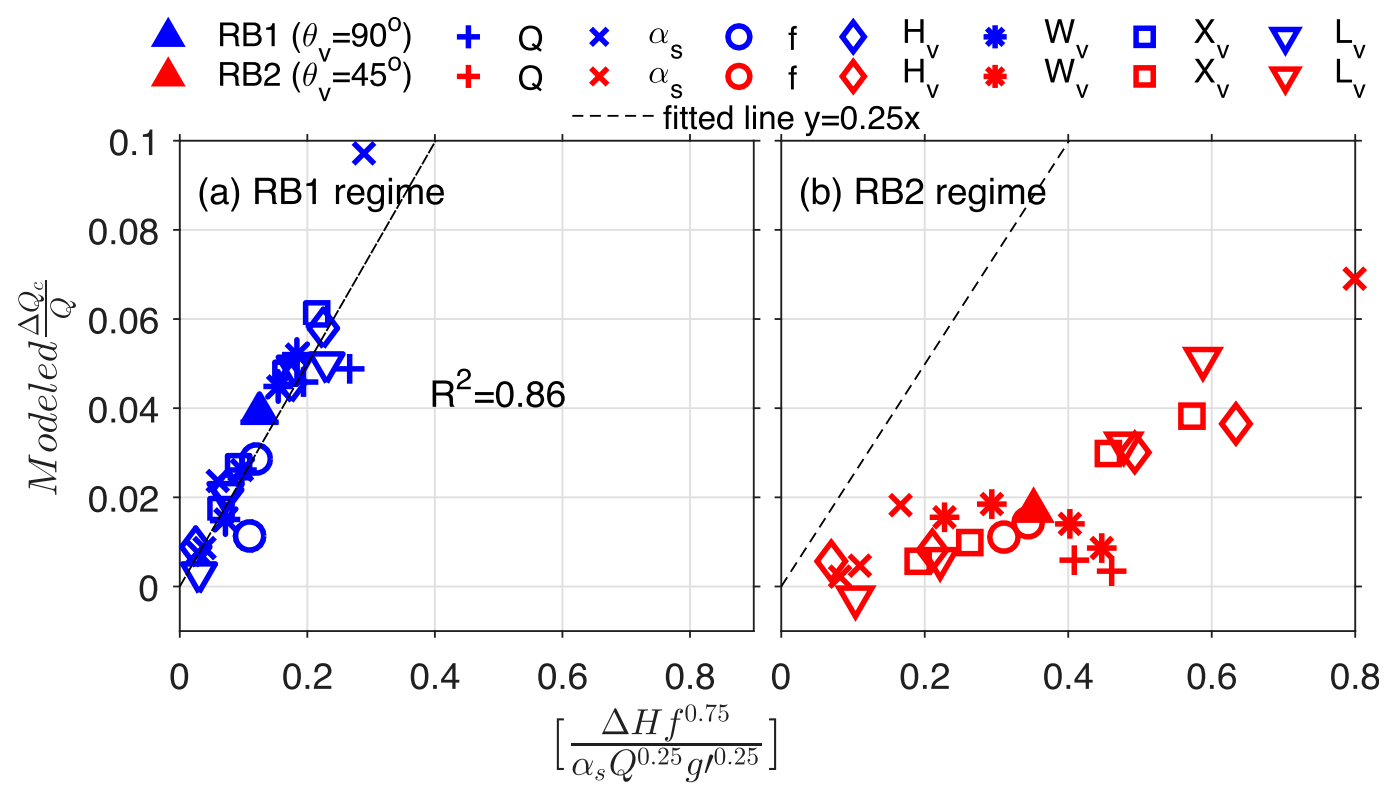

FIG. 10. Comparison of model-simulated $I$ with the scaled values based on Eq. (28) (symbols) in both regimes and results of the least-squared fit in the B1 regime (dashed lines in both panels). Each type of symbol represents comparisons obtained via altering one sensitivity parameter; the solid symbols are the base simulations. (a) Only results from sensitivity simulations in the B1 regime are shown; (b) only results from sensitivity simulations in the B2 regime are shown. The least-squared fit in (a) gives the value of the coefficient in (28), $\gamma \approx 0.25$, and an $R^{2}$ value of 0.86 .

Prior studies (e.g., Lentz and Helfrich 2002) have shown that the bulge radius $R_{b}$ scales with the baroclinic deformation radius $L_{b}=\left(2 Q g^{\prime}\right)^{0.25} / f^{0.75}$ as

$$
R_{b}=\lambda L_{b}
$$

Here, $\lambda$ is a coefficient that increases with time reflecting the growth of the bulge. RB0 gives $\lambda=0.62(t f)^{0.4}$ (appendix B) and $\lambda=4.9$ in the quasi-equilibrium state on Day 27. Substituting (27) into (26) gives a formula for valley-induced enhancement of the down-shelf freshwater transport in a fully developed unforced river plume,

$$
I \approx \frac{\gamma \Delta H f^{0.75}}{\lambda \alpha_{s, o} Q^{0.25} g^{\prime 0.25}} .
$$

Here, $\gamma$ is a coefficient to be determined empirically. This scaling formula suggests that normalized enhancement of the down-shelf freshwater transport increases with increasing $\Delta H$ (deeper/wider/longer valleys) and $f$, and decreasing $\alpha_{s}$ and $g^{\prime}$ (greater discharge salinity or fresher ambient shelf water). Note that $I$ actually increases with increasing $Q$ (Fig. 8a) even though $Q$ appears in the denominator in (28). The reason is that $\Delta H$ is not only affected by the valley geometry but also $Q$ through the bulge size. As $Q$ increases, the bulge becomes larger and occupies a larger part of the valley region, which causes $\Delta H$ to increase. The scaling in (28) has a weak and almost negligible dependence on time. As the bulge grows over time, both $\lambda$ and $\Delta H$ increase, and their time dependence largely cancel each other. This is consistent with $\Delta Q_{c} / Q$ in RB1 being largely stable after the plume reaches a quasiequilibrium state (Fig. 6d).
To validate (28), we first compare it with $I$ extracted from the sensitivity simulations in the $\mathrm{B} 1$ regime $\left(\theta_{v}=90^{\circ}\right)$ at day 27. The goal is to obtain a value of $\gamma$ that fits results of all the sensitivity simulations, indicating the applicability of (28) to all tested scenarios. Least squares fit of modeled $I$ in B1 regime to the $I$ values obtained from (28) leads to $\gamma=0.25$ with an $R^{2}$ of 0.86 (Fig. 10a). Meanwhile, for each set of the sensitivity simulations with one altered parameter (each symbol type in Fig. 10a), the model results generally align with the fitted line. It means that (28) captures the underlying dynamics of the parameters influencing the down-shelf freshwater transport.

\section{b. Valley orientation effect}

The scaling works well in the B1 regime $\left(\theta_{v}=90^{\circ}\right)$, but appears to overestimate the enhancement of the down-shelf freshwater transport for valleys of other orientations, especially those in the $\mathrm{B} 2$ regime $\left(\theta_{v}=45^{\circ}\right)$ (Fig. 10b). Close examination reveals that the discrepancy in the $\mathrm{B} 2$ regime is caused by an additional up-shelf (northward) compression of the bulge near the impingement point by the slanted valley (Figs. $3 \mathrm{~m}$ and $5 \mathrm{c}$ ). This up-shelf compression of the bulge decreases $\beta_{i}$, reduces the down-shelf momentum input into the impingement region (Fig. 11b), and then suppresses $\Delta Q_{c}$.

The up-shelf compression of the bulge in B2 regime is consistent with the geostrophic adjustment of the bulge flow to the valley bathymetry. Valleys with $\theta_{v}=45^{\circ}$ have centers to the south of the river mouth, and their geometric area covers much of the eastern half of the bulge, including the southeastern part near the impingement point (Figs. 5c and 11b). This differs from valleys in the $\mathrm{B} 1$ regime whose geometric area covers only the northeastern part of the bulge (Figs. 5b and 11a). 
(a) $\theta_{v}=90^{\circ}$

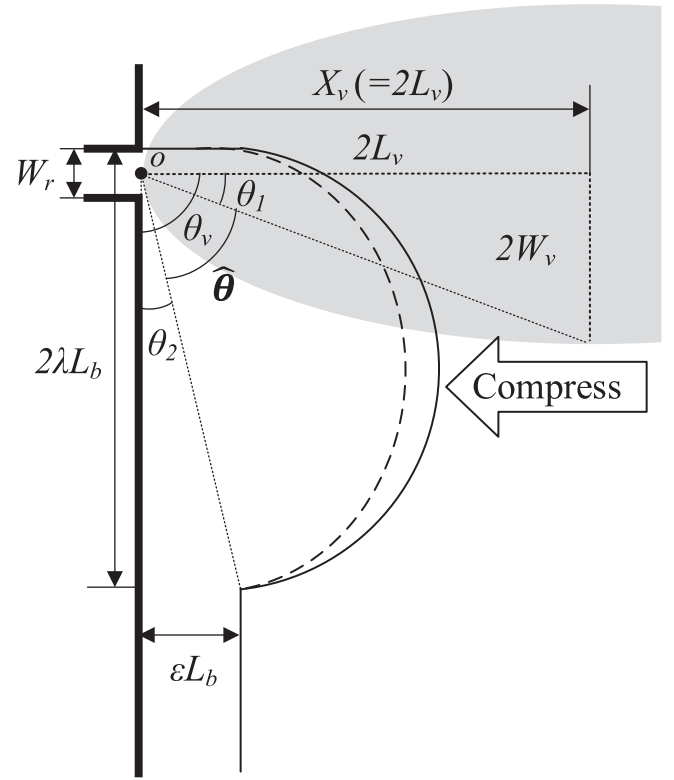

(b) $\theta_{v}=45^{\circ}$

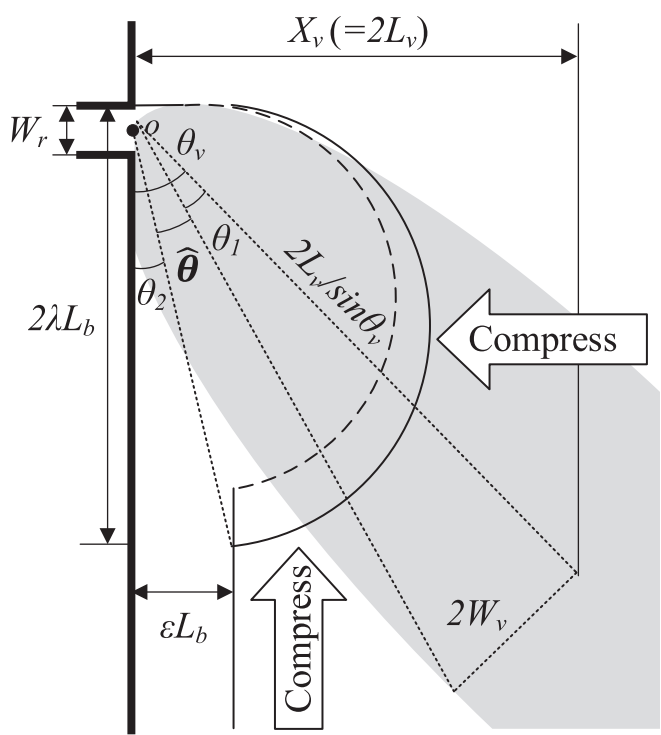

FIG. 11. Schematics showing influences of valleys in (a) B1 and (b) B2 regimes on the bulge shape and the key geometric variables. The black solid lines represent original (uncompressed) bulge, and the black dashed lines represent compressed bulge. The shade areas outline the valley.

Geostrophic adjustment to valley bathymetry occurs to part of the bulge flow that falls inside the valley geometric area and also to a part downstream of that (Fig. 5). Therefore, the valley influence area in $\mathrm{B} 1$ regimes covers the eastern part of the bulge, which results in the onshore compression of the bulge; in the $\mathrm{B} 2$ regime, the valley influence area covers the southeastern part of the bulge, resulting in a northwestward bulge compression mostly along the valley long axis. This northwestward compression can be decomposed into an onshore westward compression and an up-shelf northward compression. The up-shelf compression has the opposite effect on $\beta_{i}$ and $I$ as the onshore compression, resulting in a weakened influence of the valley on the freshwater transport in the coastal current (Fig. 6).

This effect of the valley influence area explains results of the B2-regime sensitivity simulations of different $\theta_{v}$ (Fig. 8h) and $W_{v}$ (Fig. 8e). As the valleys rotate clockwise to the south or the valleys in $\mathrm{B} 2$ regime becomes wider, their influence area moves south/southwestward, which causes stronger up-shelf compression of the bulge and reduction of $\Delta Q_{c}$. Because this effect is not considered in the scaling analysis, (28) overestimates valley-induced enhancement of the down-shelf freshwater transport.

We take a pragmatic approach to incorporate this effect on the down-shelf freshwater into the scaling of $I$. The argument above suggests that the separation between the valley influence area and the southern corner of the bulge is related to the bulge up-shelf compression. To measure the separation, we define an angle (Fig. 11b),

$$
\hat{\theta}=\theta_{v}-\theta_{1}-\theta_{2}
$$

Here,

$$
\theta_{1}=\tan ^{-1}\left(\frac{W_{v}}{L_{v}} \sin \theta_{v}\right)
$$

is the angle between the valley long axis and a line connecting the end points of the valley major and minor axes, and

$$
\theta_{2}=\tan ^{-1}\left(\frac{4 L_{b}}{4 \lambda L_{b}-W_{r}}\right)
$$

is the angle between the coast and a line connecting the river mouth center and the southern corner of the bulge (Fig. 11b). When the valley rotates clockwise, its influence area moves closer to the southern end of the bulge, $\theta_{v}$ decreases; when the valley widens, $\theta_{1}$ increases. Both result in a decrease of $\hat{\theta}$, a strengthening of the up-shelf bulge compression, and then a reduction of $\Delta Q_{c}$.

To incorporate $\hat{\theta}$ into the scaling of $I$, we multiply (28) by a dimensionless coefficient function, $f(\hat{\theta})$, which has to satisfy the conditions of $f(\hat{\theta}) \rightarrow 1$ at large $\hat{\theta}$ and $f(\hat{\theta}) \rightarrow 0$ as $\hat{\theta} \rightarrow 0$. These conditions ensure the minimum (maximum) $\Delta Q_{c}$ when the valley is far away (close to) the southern end of the bulge. For that, we empirically choose $f(\hat{\theta})=\tanh ^{2}(\pi \hat{\theta} / 180)$, which satisfies the conditions at both limits (Fig. 12) and gives good match between the scaled and modeled results (see below). The scaling of the enhancement of the quasi-equilibrium down-shelf freshwater transport becomes

$$
I \approx \tanh ^{2}\left(\frac{\pi \hat{\theta}}{180}\right) \frac{\gamma^{\prime} \Delta H f^{0.75}}{\lambda \alpha_{s, o} Q^{0.25} g^{\prime 0.25}} .
$$

where $\gamma^{\prime}$ is a new empirical coefficient. This new scaling formula qualitatively captures the dependence of $\Delta Q_{c}$ on all of the parameters (Fig. 8), including the negative relation between 


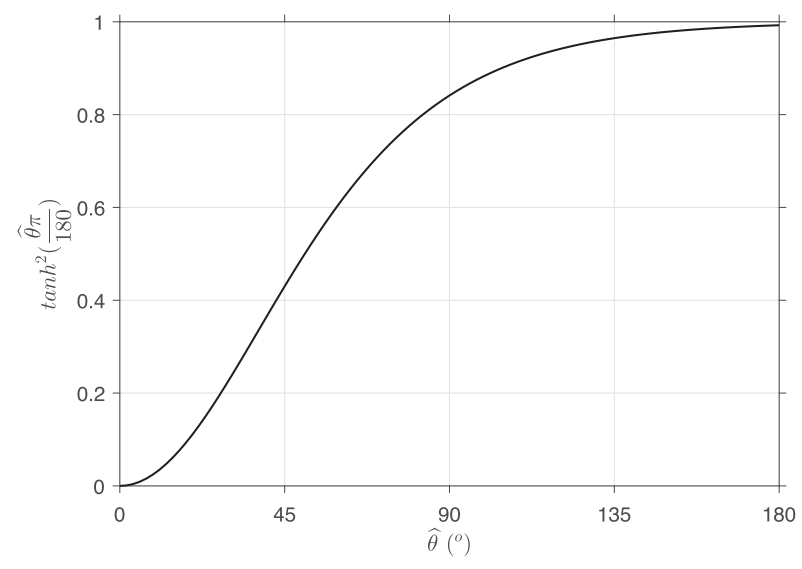

FIG. 12. The dependence of $\tanh ^{2}(\pi \hat{\theta} / 180)$ on $\hat{\theta}$.

$\Delta Q_{c}$ and $W_{v}$ in the $\mathrm{B} 2$ regime and the nonlinear dependence of $\Delta Q_{c}$ on $\theta_{v}$. There are relatively large mismatches between the modeled and scaled values of $I$ in a few simulations, e.g., $Q=$ $10^{5} \mathrm{~m}^{3} \mathrm{~s}^{-1}$ (Fig. 8a) and $f_{0}=1.13 \times 10^{-4} \mathrm{~s}^{-1}$ (Fig. 8b). Close examination shows that the bulges and coastal currents in those simulations of maximum discharge or maximum Coriolis develop large-amplitude meanders, which affects the quantification of $Q_{c}$. Comparison of modeled $I$ from all sensitivity simulations, including those in B1 and B2 regimes and with altered value of $\theta_{v}$, with (32) gives a good general alignment (Fig. 13) with $\gamma^{\prime}=$ 0.47 and $R^{2}$ of 0.81 . It indicates that our scaling analysis captures the dynamics of valley influence on freshwater transport in river plumes in the idealized scenarios considered here.

The analysis here indicates that valley influence on the freshwater transport in the coastal current is generally weak but persistent. For a fully developed Changjiang River plume, $Q=5 \times 10^{3}-1.1 \times 10^{5} \mathrm{~m}^{3} \mathrm{~s}^{-1} ; \alpha_{s, o} \approx 2.5 \times 10^{-4} ; g^{\prime} \approx 0.2 \mathrm{~m} \mathrm{~s}^{-2} ;$ $f=7.3 \times 10^{-5} \mathrm{~s}^{-1} ; \Delta H \approx 2 \mathrm{~m} ; W_{v}=25 \mathrm{~km} ; L_{v}=75 \mathrm{~km} ; \theta_{v} \approx$ $45^{\circ}$; and $\lambda \approx 5$. Applying these in (32) gives $I=0.8 \%-1.2 \%$. Thus, the valley off the mouth of Changjiang River, in the unforced scenario considered in this study, would enhance the freshwater transport in the southward coastal current only slightly. Note that the weak valley influence on the Changjiang plume is further diminished by the orientation of the valley.

However, the valley influence could be more substantial at other places or on other aspect of the river plume. As $I$ increases with increasing $f$, increasing $\hat{\theta}$, increasing $\Delta H$, and decreasing $\alpha$, the normalized influence of valley bathymetry on the freshwater transport in the coastal current would be more pronounced at a high-latitude river discharging onto a relatively flat shelf incised by a deep and large valley with major axis normal to the coast. Moreover, the weak valley influence could accumulate over time and lead to more substantial modification of the nearshore stratification farther down-shelf or the cross-shelf distribution of

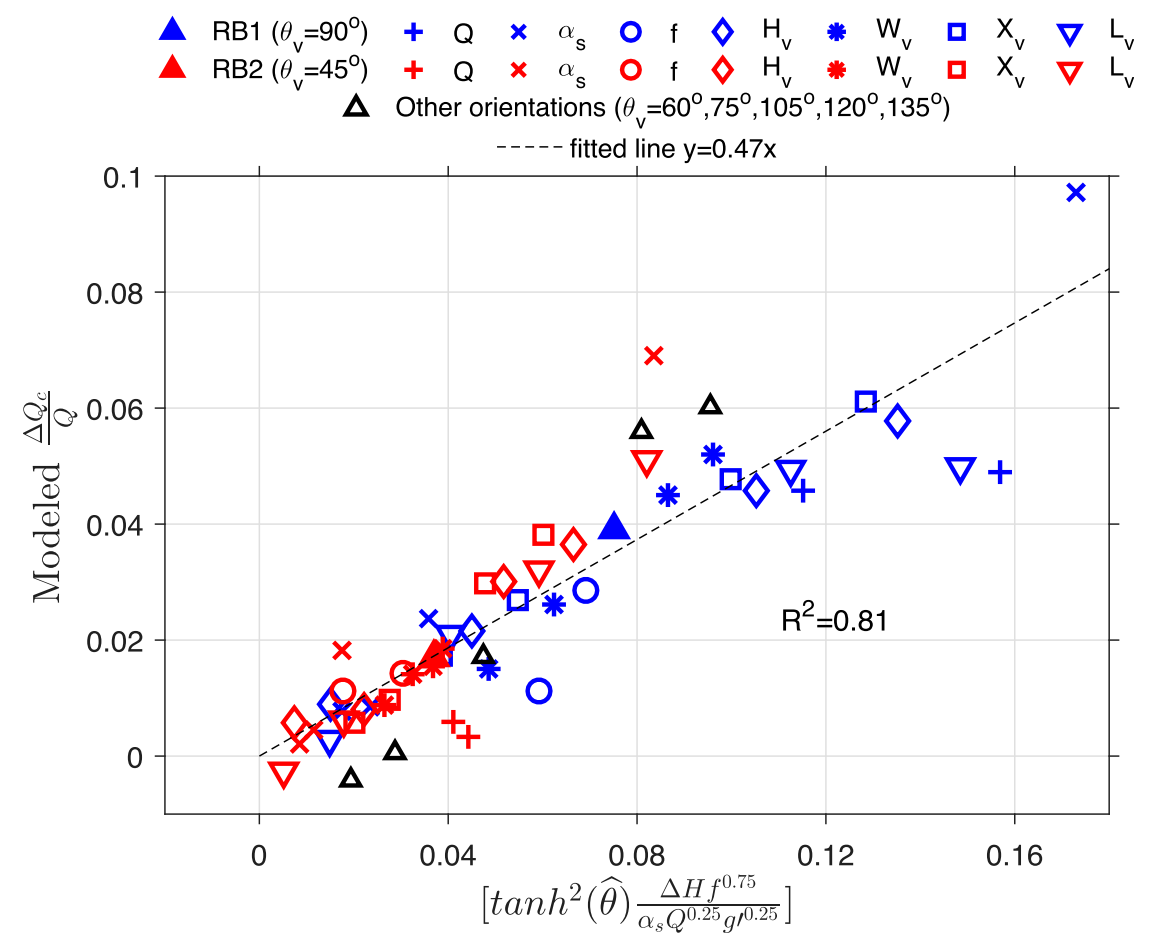

FIG. 13. Comparison of model-simulated $I$ with analytically scaled values from Eq. (32) (symbols) and results of the least squares fit (dashed line). Each type of symbol represents comparisons obtained via altering one sensitivity parameter; blue and red solid symbols represent B1 and B2 simulations, respectively, and black symbols represent simulations of different valley orientation. The least squares fit here with all the simulations gives the value of the coefficient in (32), $\gamma^{\prime}=0.47$, and an $R^{2}$ value of 0.81 . 
riverine sediment in the river mouth region. As sediment settling and transport processes are highly nonlinear and sensitive to the flow, smaller changes in the plume behavior could result in substantial alteration in the deposition of riverine sediment, which over time could affect the shelf morphology.

In the real ocean, changes of the plume freshwater transport in the magnitude resolved by this study are likely overshadowed by variability induced by other factors, such as fluctuating river discharge or winds. However, it is also possible that, through inducing stronger shelf flows, external forcing, such as tides and winds, could actually strengthen the coupling between the surface plume and the valley bathymetry, and then enhance the valley influence on the river plume. Neither tides nor winds are considered in this study, and their impact on the valley influence is left for future studies.

\section{Summary}

This study focuses on the response of fully developed surface-trapped river plumes in their quasi-equilibrium state to valley bathymetry over a sloping bottom. Previous studies showed impacts of shelf valleys on riverine plume dispersal, but the mechanism was not examined. We set up an idealized model in the context of Changjiang River to simulate unforced spreading of surface-trapped freshwater plumes over a sloping bottom incised by a shallow valley. The potential influences of tides and surface forcing are neglected here. General pattern of the plumes in this study is similar to those presented in literature. It consists of a growing anticyclonic bulge followed by a down-shelf coastal current. Our simulations show that under the idealized scenarios considered here shelf valleys do not alter the basic pattern of the river plume, but they do exert some secondary but persistent influence on the river plume. In particular, shelf valleys tend to compress the bulge toward the coast and slightly enhance down-shelf freshwater transport in the coastal current. Analysis of the model results reveals that the bulge compression results from geostrophic adjustment of the depth-averaged flow in the bulge region to the valley bathymetry, i.e., tendency of the barotropic flow to follow isobaths to conserve potential vorticity. Onshore compression of the bulge increases the incident angle of the bulge flow impinging toward the coast and strengthens the down-shelf momentum flux toward the impingement point, which then pushes more freshwater into the down-shelf coastal current.

Sensitivity simulations demonstrate that valley-induced enhancement of the down-shelf freshwater transport $\Delta Q_{c}$ varies with river discharge, Coriolis parameter $f$, ambient shelf bottom slope $\alpha_{s}$, and valley geometric parameters. The dependence of $\Delta Q_{c}$ on $f$ and $\alpha_{s}$ reflects the influence of slope Burger number, $\mathrm{Bu}$. As $\mathrm{Bu}$ increases, stronger stratification effect makes the bulge flow less sensitive to the bathymetry and leads to a smaller $\Delta Q_{c}$. Geometric parameters of the valley can affect $\Delta Q_{c}$ through two different ways: 1 ) they modify valley-induced depth change in the bulge region, potential vorticity of the depth-averaged flow, and then the onshore compression of the bulge, and 2) they also change the valley influence area and then the down-shelf momentum input of the bulge flow into the impingement region.

Applying potential vorticity conservation in the bulge region, an analytical scaling is derived for enhancement of the quasi-equilibrium down-shelf freshwater transport in the coastal current induced by a shelf valley. The effect of valley orientations is then incorporated into the scaling as an empirical coefficient depending on an angular separation between the valley and the coast. The combined formula, (32), captures the dependence of $\Delta Q_{c}$ on all sensitivity parameters. It also gives values of the normalized enhancement of down-shelf freshwater transport in good agreement with sensitivity simulations, indicating that the scaling analysis captures mechanisms of shelf valleys influencing spreading of unforced river plumes.

The results here indicate that valley-induced change in freshwater transport of the unforced surface-trapped river plume at any instant time is small, mostly $<7 \%$ of the river discharge. However, it is possible that long-term accumulation of the weak valley influence on the plume could interact with other nonlinear processes, such as sediment transport, and potentially lead to more substantial impact on the coastal environment. In the real ocean, external forcing, e.g., tides and winds, could, on one hand, smear the weak valley influence, but, on the other hand, enhance the valley influence through strengthen the connection between surface plume flow and the bathymetry. How the external forcing would modify the valley influence remains unknown. Nevertheless, mechanisms of valley influence on plume freshwater transport revealed here are generic and provide a basis for future studies of bathymetric influence on river plumes under more realistic conditions.

Acknowledgments. This work is conducted by Canbo Xiao and Weifeng (Gordon) Zhang during CX's one-year visit at Woods Hole Oceanographic Institution (WHOI) in 2018-19. CX was supported by China Scholarship Council. We thank Steven Lentz and Rocky Geyer for helpful discussion during the course of the study.

Data availability statement. This study does not include any observational data. The models presented in this study are idealized simulations and do not belong to any of the data categories requiring archiving as defined in AMS Data Archiving and Citation Guidelines.

\section{APPENDIX A}

\section{Notations}

Table A1 provides a list of notations, their meanings, and indicates where each first appears.

\section{APPENDIX B}

\section{Bulge Geometric Relations}

Figure 9 shows idealized geometry of the bulges with and without onshore compression. Following prior studies (e.g., Avicola and Huq 2002), we assume the bulge outer boundaries being circular. In its original uncompressed form, the bulge has a radius $R_{b}$, and the coastal current has a width $W_{c}$. They both are proportional to the baroclinic deformation radius 
TABLE A1. List of notations.

\begin{tabular}{|c|c|c|}
\hline Variables & Meaning & $\begin{array}{c}\text { First } \\
\text { appearance }\end{array}$ \\
\hline$A_{c}$ & $\begin{array}{l}\text { Cross-sectional area of the coastal } \\
\text { current }\end{array}$ & Section 3 \\
\hline$A_{b}$ & Bulge horizontal area & Section 5 \\
\hline $\mathrm{Bu}$ & Burger number of the plume flow & Section 2 \\
\hline$C_{d}$ & Coefficient of quadratic bottom drag & Section 2 \\
\hline$f$ & Coriolis parameter on a $\beta$ plane & Eq. (1) \\
\hline$f_{0}$ & $\begin{array}{l}\text { Coriolis parameter at the midpoint of } \\
\text { the estuary }\end{array}$ & Section 1 \\
\hline$g$ & Gravitational acceleration & Section 2 \\
\hline$g^{\prime}$ & Reduced gravity & Section 2 \\
\hline$H$ & Mean water depth within the bulge & Section 2 \\
\hline$H_{c}$ & Water depth on the coastal wall & Eq. (4) \\
\hline$H_{p}$ & Plume thickness along the coastal wall & Eq. (4) \\
\hline$H_{v}$ & Valley depth scale & Eq. (4) \\
\hline$h$ & Water depth & Eq. (4) \\
\hline$I$ & $\begin{array}{l}\text { Normalized enhancement of freshwater } \\
\text { transport in the coastal current }\end{array}$ & Eq. (23) \\
\hline$L_{b}$ & $\begin{array}{l}\text { Baraclinic deformation radius of the } \\
\text { river outflow }\end{array}$ & Section $3 a$ \\
\hline$L_{i}$ & Inertia radius of the river outflow & Section $3 a$ \\
\hline$L_{v}$ & Valley length scale parameter & Eq. (5) \\
\hline$N_{a}$ & $\begin{array}{l}\text { Buoyancy frequency on the } \\
\text { ambient shelf }\end{array}$ & Section 2 \\
\hline$N_{s}$ & Buoyancy frequency in the bulge region & Eq. (6) \\
\hline$p$ & Pressure & Eq. (10) \\
\hline$Q$ & River freshwater discharge & Eq. (1) \\
\hline$\widetilde{Q}_{c}$ & $\begin{array}{l}\text { Freshwater transport in the coastal } \\
\text { current }\end{array}$ & Eq. (1) \\
\hline$R_{b}$ & Bulge radius & Section $3 b$ \\
\hline Ro & Rossby number of the plume flow & Section 2 \\
\hline $\mathrm{Ro}_{d}$ & Rossby number of thce river discharge & Eq. (2) \\
\hline$S$ & Model-simulated salinity & Eq. (8) \\
\hline$S_{0}$ & Model initial salinity & Section 2 \\
\hline$T_{0}$ & Model initial temperature & Section 2 \\
\hline$t$ & Time variable & Section $3 b$ \\
\hline$U_{0}$ & River outflow speed & Section 1 \\
\hline$u$ & Cross-shelf velocity & Eq. (10) \\
\hline$v$ & Along-shelf velocity & Eq. (8) \\
\hline$v_{a}$ & $\begin{array}{l}\text { Azimuthal velocity of water at the outer } \\
\text { edge of the bulge }\end{array}$ & Section $3 b$ \\
\hline$V_{\theta}$ & Surface azimuthal velocity of the bulge & Fig. 4 \\
\hline$W_{b}$ & Bulge width & Section $3 b$ \\
\hline$W_{b}^{\prime}$ & Area-based width scale of the bulge & Eq. (16) \\
\hline$W_{c}$ & Width of the down-shelf coastal current & \\
\hline$W_{r}$ & River mouth width & Section 1 \\
\hline$W_{v}$ & Valley width scale & Eq. (5) \\
\hline$X_{c}$ & $\begin{array}{l}\text { Offshore location of the bulge rotation } \\
\text { center }\end{array}$ & Section $5 \mathrm{a}$ \\
\hline$\left(X_{v}, Y_{v}\right)$ & Coordinate of the valley center & Section 2 \\
\hline$x$ & $\begin{array}{l}x \text { axis of the Cartesian coordinate } \\
\text { system, positive offshore }\end{array}$ & Section 2 \\
\hline$y$ & $\begin{array}{l}y \text { axis of the Cartesian coordinate } \\
\text { system, positive northward } \\
\text { along-shelf }\end{array}$ & Section 2 \\
\hline$z$ & $\begin{array}{l}z \text { axis of the Cartesian coordinate } \\
\text { system, positive upward }\end{array}$ & Section 2 \\
\hline$\alpha_{s}$ & Slope of the ambient shelf & Section 1 \\
\hline$\beta$ & Beta-plane parameter & Section 1 \\
\hline
\end{tabular}

TABLE A1. (Continued)

\begin{tabular}{|c|c|c|}
\hline Variables & Meaning & $\begin{array}{c}\text { First } \\
\text { appearance }\end{array}$ \\
\hline$\gamma$ & $\begin{array}{l}\text { Empirical coefficient in the scaled } \\
\text { formula (28) }\end{array}$ & Eq. (28) \\
\hline$\beta_{i}$ & $\begin{array}{l}\text { Angle of the bulge incident flow relative } \\
\text { to the cross-shelf direction }\end{array}$ & Section 1 \\
\hline$\zeta$ & $\begin{array}{l}\text { Relative vorticity of depth-averaged } \\
\text { flow within the bulge }\end{array}$ & Eq. (7) \\
\hline$\varepsilon$ & Coefficient factor between $W_{c}$ and $L_{R}$ & Appendix B \\
\hline$\eta$ & Sea surface level & Eq. (10) \\
\hline$\hat{\theta}$ & $\begin{array}{l}\text { Angle measuring the separation } \\
\text { between the valley influence area and } \\
\text { the southern corner of the bulge }\end{array}$ & Eq. (29) \\
\hline$\theta_{1}$ & $\begin{array}{l}\text { Angle between the valley long axis and a } \\
\text { line connecting the end points of the } \\
\text { valley major and minor axes }\end{array}$ & Eq. (29) \\
\hline$\theta_{2}$ & $\begin{array}{l}\text { Angle between the coast and a line } \\
\text { connecting the river mouth center and } \\
\text { the southern corner of the bulge }\end{array}$ & Eq. (29) \\
\hline$\theta_{v}$ & $\begin{array}{l}\text { Orientation angle of the valley long axis } \\
\text { relative to the negative y direction }\end{array}$ & Eq. (5) \\
\hline$\lambda$ & Coefficient factor between $R_{b}$ and $L_{b}$ & Appendix B \\
\hline$\xi$ & Bulge surface relative vorticity & Eq. (1) \\
\hline$\rho_{0}$ & Reference density & Eq. (10) \\
\hline$\rho_{b}$ & Mean bottom density within the bulge & Section 2 \\
\hline$\rho_{s}$ & Mean surface density within the bulge & Section 2 \\
\hline$\tau_{b x}$ & Bottom stress in the cross-shelf direction & Eq. (10) \\
\hline$\omega$ & $\begin{array}{l}\text { Rotational speed of the bulge } \\
\text { surface flow }\end{array}$ & Section $3 b$ \\
\hline$\Delta H$ & $\begin{array}{l}\text { Mean depth increase in the bulge area } \\
\text { induced by the valley }\end{array}$ & Eq. (19) \\
\hline$\Delta Q_{c}$ & $\begin{array}{l}\text { Enhancement of freshwater transport in } \\
\text { the coastal current }\end{array}$ & Section $4 b$ \\
\hline$\Delta V$ & $\begin{array}{l}\text { Volume increase in the bulge area } \\
\text { induced by the valley }\end{array}$ & Eq. (18) \\
\hline$\Delta \alpha$ & Uniform slope change & Eq. (18) \\
\hline$\Pi$ & $\begin{array}{l}\text { Potential vorticity of depth-averaged } \\
\text { flow in the bulge area }\end{array}$ & Section $3 b$ \\
\hline
\end{tabular}

$L_{b}=\left(2 Q g^{\prime}\right)^{0.25} / f^{0.75}$ (Lentz and Helfrich 2002) with $R_{b}=\lambda L_{b}$ and $W_{c}=\varepsilon L_{b}$, where $\lambda$ and $\varepsilon$ are coefficients. We examine the variation of $R_{b}$ and $W_{c}$ in a number of simulations with no valley and determine that $\lambda \approx 0.62(t f)^{0.4}$ (Fig. B1) and $\varepsilon \approx 2$. The offshore location of the bugle center, $X_{c}$, also changes with time. Horner-Devine et al. (2006) suggests that $X_{c}$ is proportional to the inertial length scale, $L_{i}=U_{0} / f$. Consistently, our simulations indicate that $X_{c} \approx \lambda L_{i}$.

Our simulations indicate that $R_{b}$ and $W_{c}$ do not change with the ambient shelf slope, consistent with $L_{b}$ being independent of the bottom slope. The bulge compression is largely caused by onshore migration of the bulge rotation center from $X_{c, w}$ to $X_{c, o}$ (Fig. 9). The incident angles of the original and compressed bulge, $\beta_{i, o}$ and $\beta_{i, w}$, thus satisfy

$$
\sin \beta_{i, o}=\frac{W_{c}-X_{c, o}}{R_{b}} ; \quad \sin \beta_{i, w}=\frac{W_{c}-X_{c, w}}{R_{b}},
$$

respectively. The outer edge of the bulges with and without the slope change satisfy 


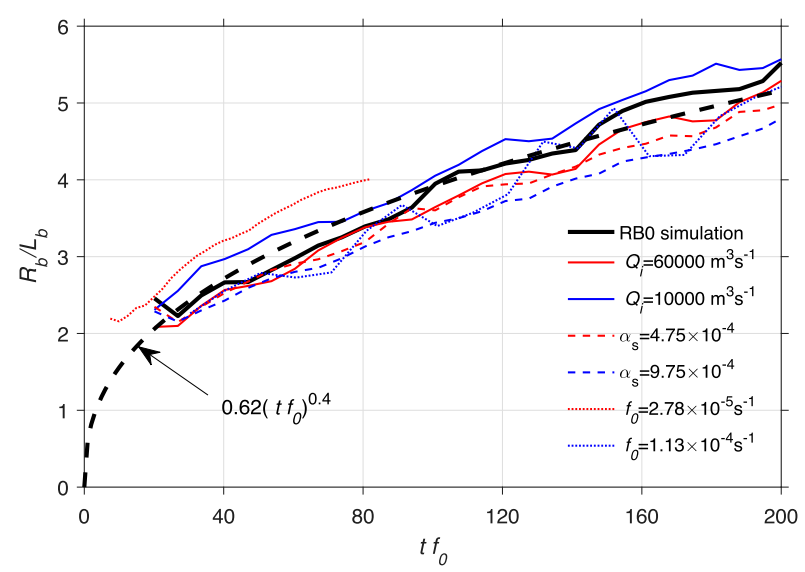

FIG. B1. Time series of the ratio $R_{b} / L_{b}$ with $R_{b}$ denoting modeled bulge radius and $L_{b}=\left(2 Q g^{\prime}\right)^{0.25} / f^{0.75}$ denoting the baroclinic radius of deformation. The thick black solid line and thin color lines are from simulations with no valley: RB0 and simulations with one parameter different from RB0 as shown in the legend. The thick black dashed line is the exponential fit of $\lambda=0.62\left(t f_{0}\right)^{0.4}$.

$$
\left(x_{w}-X_{c, w}\right)^{2}+y^{2}=R_{b}^{2} ; \quad\left(x_{o}-X_{c, o}\right)^{2}+y^{2}=R_{b}^{2},
$$

respectively. The area-based width scale of the bulges in (17) can be derived as

$$
W_{b, w}^{\prime}=\frac{\int_{A_{b, w}} x d A}{\int_{A_{b, w}} d A}=\frac{\int_{-R_{b}}^{R_{b}} \int_{0}^{x_{w}} x d x d y}{\int_{-R_{b}}^{R_{b}} \int_{0}^{x_{w}} d x d y}=\frac{\int_{0}^{R_{b}} x_{w}^{2} d y}{2 \int_{0}^{R_{b}} x_{w} d y},
$$

and

$$
W_{b, o}^{\prime}=\frac{\int_{A_{b, o}} x d A}{\int_{A_{b, o}} d A}=\frac{\int_{-R_{b}}^{R_{b}} \int_{0}^{x_{o}} x d x d y}{\int_{-R_{b}}^{R_{b}} \int_{0}^{x_{o}} d x d y}=\frac{\int_{0}^{R_{b}} x_{o}^{2} d y}{2 \int_{0}^{R_{b}} x_{o} d y},
$$

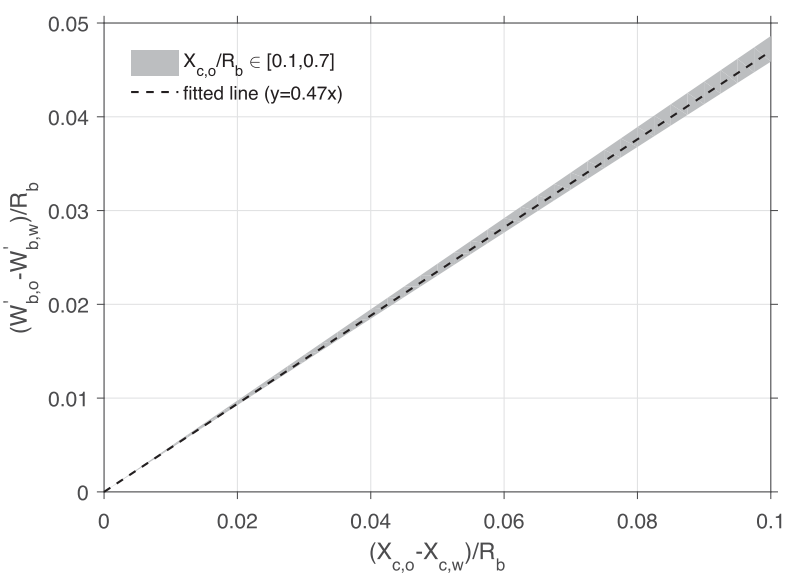

FIG. B2. Quasi-linear dependence of $\left(W_{b, o}^{\prime}-W_{b, w}^{\prime}\right) / R_{b}$ on $\left(X_{c, o}-X_{c, w}\right) / R_{b}$ revealed by numerical calculation of normalized (B3) and (B4). where $x_{o}=\left(R_{b}^{2}-y^{2}\right)^{1 / 2}+X_{c, o}$ and $x_{w}=\left(R_{b}^{2}-y^{2}\right)^{1 / 2}+X_{c, w}$, as in (B2).

We normalize (B3) and (B4) by $R_{b}$ and then solve them numerically for various idealized bulge shapes with $X_{c, o} / R_{b} \in$ $[0.1,0.7]$ that covers the parameter space of the interests of this study. Note that $X_{c, o} / R_{b}=0.7$ is a critical value of bulges becoming unstable (Horner-Devine et al. 2006). The numerical solution gives a quasi-linear relation between $W_{b, o}^{\prime}-W_{b, w}^{\prime}$ and $X_{c, o}-X_{c, w}$ (Fig. B2) as

$$
W_{b, o}^{\prime}-W_{b, w}^{\prime} \approx 0.47\left(X_{c, o}-X_{c, w}\right) .
$$

\section{REFERENCES}

Allen, S. E., and X. Durrieu de Madron, 2009: A review of the role of submarine canyons in deep-ocean exchange with the shelf. Ocean Sci., 5, 607-620, https://doi.org/10.5194/os-5-607-2009.

Avicola, G., and P. Huq, 2002: Scaling analysis for the interaction between a buoyant coastal current and the continental shelf: Experiments and observations. J. Phys. Oceanogr., 32, 3233-3248, https://doi.org/10.1175/15200485(2002)032<3233:SAFTIB > 2.0.CO;2.

— and - 2003a: The characteristics of the recirculating bulge region in coastal buoyant outflows. J. Mar. Res., 61, 435-463, https://doi.org/10.1357/002224003322384889.

— mation of the recirculating bulge region in coastal buoyant outflows. J. Mar. Res., 61, 411-434, https://doi.org/10.1357/ 002224003322384870.

Beardsley, R. C., R. Limeburner, H. Yu, and G. A. Cannon, 1985: Discharge of the Changjiang (Yangtze River) into the East China Sea. Cont. Shelf Res., 4, 57-76, https://doi.org/10.1016/ 0278-4343(85)90022-6.

Chant, R. J., S. M. Glenn, E. Hunter, J. Kohut, R. F. Chen, R. W. Houghton, J. Bosch, and O. Schofield, 2008: Bulge formation of a buoyant river outflow. J. Geophys. Res., 113, C01017, https:// doi.org/10.1029/2007JC004100.

Chao, S. Y., and W. C. Boicourt, 1986: Onset of estuarine plumes. J. Phys. Oceanogr., 16, 2137-2149, https://doi.org/10.1175/ 1520-0485(1986)016<2137:OOEP > 2.0.CO;2.

Chapman, D. C., 1985: Numerical treatment of cross-shelf open boundaries in a barotropic coastal ocean model. J. Phys. Oceanogr., 15, 1060-1075, https://doi.org/10.1175/1520-0485(1985) 015<1060:NTOCSO > 2.0.CO;2.

Chen, S. N., 2014: Enhancement of alongshore freshwater transport in surface-advected river plumes by tides. J. Phys. Oceanogr., 44, 2951-2971, https://doi.org/10.1175/JPO-D-14-0008.1.

Choi, B. J., and J. L. Wilkin, 2007: The effect of wind on the dispersal of the Hudson River plume. J. Phys. Oceanogr., 37, 1878-1897, https://doi.org/10.1175/JPO3081.1.

Crockett, J. C., C. A. Nittrouer, A. S. Ogston, D. F. Naar, and T. T. Donahue, 2008: Morphology and filling of incised submarine valleys on the continental shelf near the mouth of the Fly River, Gulf of Papua. J. Geophys. Res., 113, F01S12, https:// doi.org/10.1029/2006JF000674.

Dzwonkowski, B., and X. H. Yan, 2005: Tracking of a Chesapeake Bay estuarine outflow plume with satellite-based ocean color data. Cont. Shelf Res., 25, 1942-1958, https://doi.org/10.1016/ j.csr.2005.06.011.

Flather, R. A., 1976: A tidal model of the north-west European continental shelf. Mem. Soc. Roy. Sci. Liege, 10, 141-164. 
Fong, D. A., and W. R. Geyer, 2001: Response of a river plume during an upwelling favorable wind event. J. Geophys. Res., 106, 1067-1084, https://doi.org/10.1029/2000JC900134.

, and - 2002: The alongshore transport of freshwater in a surface-trapped river plume. J. Phys. Oceanogr., 32, 957-972, https:// doi.org/10.1175/1520-0485(2002)032<0957:TATOFI >2.0.CO;2.

Garvine, R. W., 1995: A dynamical system for classifying buoyant coastal discharges. Cont. Shelf Res., 15, 1585-1596, https:// doi.org/10.1016/0278-4343(94)00065-U.

Harris, C. K., B. Butman, and P. Traykovski, 2003: Winter-time circulation and sediment transport in the Hudson Shelf Valley. Cont. Shelf Res., 23, 801-820, https://doi.org/10.1016/S02784343(03)00025-6.

Horner-Devine, A. R., D. A. Fong, S. G. Monismith, and T. Maxworthy, 2006: Laboratory experiments simulating a coastal river inflow. J. Fluid Mech., 555, 203-232, https:// doi.org/10.1017/S0022112006008937.

Jurisa, J. T., and R. J. Chant, 2013: Impact of offshore winds on a buoyant river plume system. J. Phys. Oceanogr., 43, 25712587, https://doi.org/10.1175/JPO-D-12-0118.1.

Lee, J., and A. Valle-Levinson, 2012: Influence of bathymetry on hydrography and circulation at the region between an estuary mouth and the adjacent continental shelf. Cont. Shelf Res., 41, 77-91, https://doi.org/10.1016/j.csr.2012.04.006.

- , and - 2013: Bathymetric effects on estuarine plume dynamics. J. Geophys. Res. Oceans, 118, 1969-1981, https:// doi.org/10.1002/jgrc.20119.

Lentz, S. J., and K. R. Helfrich, 2002: Buoyant gravity currents along a sloping bottom in a rotating fluid. J. Fluid Mech., 464, 251-278, https://doi.org/10.1017/S0022112002008868.

_ - B. Butman, and C. Harris, 2014: The vertical structure of the circulation and dynamics in Hudson Shelf Valley. J. Geophys. Res. Oceans, 119, 3694-3713, https://doi.org/10.1002/2014JC009883.

Liu, Z., and J. Gan, 2015: Upwelling induced by the frictional stress curl and vertical squeezing of the vortex tube over a submerged valley in the East China Sea. J. Geophys. Res. Oceans, 120, 2571-2587, https://doi.org/10.1002/2015JC010715.
Manning, J. P., L. Y. Oey, D. Packer, J. Vitaliano, T. W. Finneran, K. W. You, and S. Fromm, 1994: Observations of bottom currents and estimates of resuspended sediment transport at the New York Bight 12-mile dumpsite. J. Geophys. Res., 99, 10 221-10 239, https://doi.org/10.1029/93JC03273.

Masse, A. K., 1990: Withdrawal of shelf water into an estuary: A barotropic model. J. Geophys. Res., 95, 16 085-16 096, https:// doi.org/10.1029/JC095iC09p16085.

Michels, K. H., A. Suckow, M. Breitzke, H. R. Kudrass, and B. Kottke, 2003: Sediment transport in the shelf canyon "Swatch of No Ground" (Bay of Bengal). Deep-Sea Res. II, 50, 1003-1022, https://doi.org/10.1016/S0967-0645(02)00617-3.

Nof, D., and T. Pichevin, 2001: The ballooning of outflows. J. Phys. Oceanogr., 31, 3045-3058, https://doi.org/10.1175/ 1520-0485(2001)031<3045:TBOO >2.0.CO;2.

Uchupi, E., N. Driscoll, R. D. Ballard, and S. T. Bolmer, 2001: Drainage of late Wisconsin glacial lakes and the morphology and late quaternary stratigraphy of the New Jerseysouthern New England continental shelf and slope. Mar. Geol., 172, 117-145, https://doi.org/10.1016/S0025-3227(00) 00106-7.

Whitehead, J. A., 1985: The deflection of a baroclinic jet by a wall in a rotating fluid. J. Fluid Mech., 157, 79-93, https://doi.org/ 10.1017/S0022112085002312.

Yankovsky, A. E., and D. C. Chapman, 1997: A simple theory for the fate of buoyant coastal discharges. J. Phys. Oceanogr., 27, 1386-1401, https://doi.org/10.1175/1520-0485(1997)027<1386: ASTFTF $>2.0 . \mathrm{CO} ; 2$.

Zhang, W. G., and S. J. Lentz, 2017: Wind-driven circulation in a shelf valley. Part I: Mechanism of the asymmetrical response to along-shelf winds in opposite directions. J. Phys. Oceanogr., 47, 2927-2947, https://doi.org/10.1175/JPO-D17-0083.1.

— J. L. Wilkin, and R. J. Chant, 2009: Modeling the pathways and mean dynamics of river plume dispersal in the New York bight. J. Phys. Oceanogr., 39, 1167-1183, https://doi.org/ 10.1175/2008JPO4082.1. 